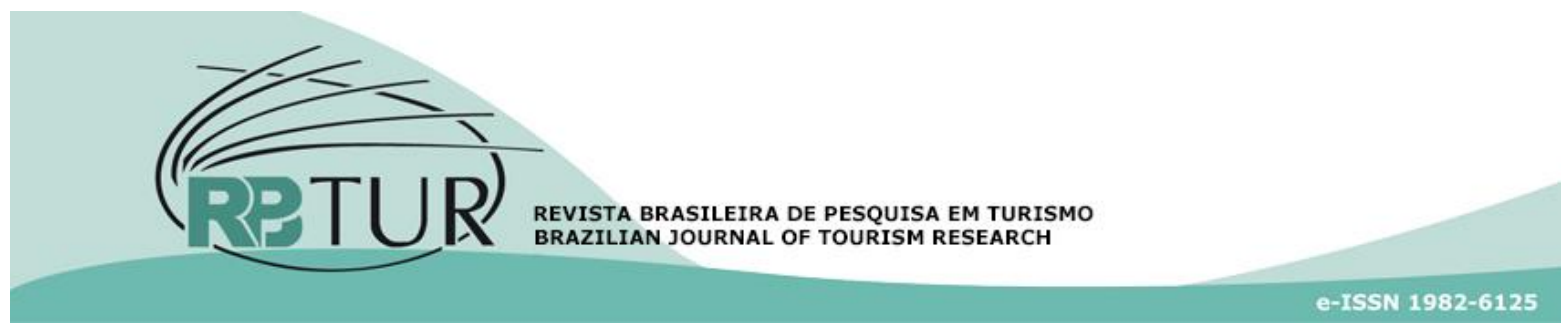

\title{
Artigos
}

\section{Revisão sistemática da literatura sobre Turismo Científico}

\section{Systematic review of the literature in Scientific Tourism}

\section{Revisión sistemática de la literatura en Turismo Científico}

\section{Bruna Ranção Conti; Maria Jaqueline Elicher²; Joice Lavandoski ${ }^{1}$}

1 Universidade Federal do Estado Rio de Janeiro (UNIRIO); Universidade Federal Fluminense (UFF), Rio de Janeiro, RJ, Brazil.

2 Universidade Federal do Estado do Rio de Janeiro (UFRJ), Rio de Janeiro, RJ, Brazil

Palavras-chave:

Turismo Científico Revisão Sistemática; Bibliometria.

Keywords:

Scientific Tourism; Systematic Review; Bibliometrics.

\section{Resumo}

Este trabalho tem como objetivo apresentar uma revisão sistemática da literatura sobre Turismo Científico, nos contextos nacional e internacional. Por meio de pesquisa exploratória e de revisões sistemática e bibliométrica da literatura, nas bases de dados "Web of Science", "Scopus" e "Publicações de Turismo", buscou-se verificar a produção em formato de artigo científico relacionada ao termo "Turismo Científico". Foram analisados quali-quantitativamente 32 artigos científicos, por meio da utilização dos softwares Mendeley, Excel, QGIS e IRAMUTEQ. Foram também verificadas as leis que regem os estudos bibliométricos. Os principais resultados apontam para uma concentração de estudos no ano de 2016 e oriundos de países europeus, sobretudo da Polônia. Os artigos foram publicados em 23 periódicos de 13 países, com destaque para: "Ido Movement for Culture", "Annals of Tourism Research" e "Revista Brasileira de Ecoturismo". Foram identificados 65 autores ou coautores, sendo os principais os poloneses Wojciech J. Cynarski e Krzysztof Kubala. A categorização dos temas em torno do Turismo Científico reúne discussões sobre eventos e viagens científicas, turismo de natureza, educação, geoturismo e desenvolvimento socioeconômico. Por fim, evidencia-se a necessidade de publicações que aprofundem a discussão teórica sobre Turismo Científico.

Abstract

This work aims to present a systematic review of the literature on Scientific Tourism, in the Brazilian and international contexts. Through exploratory research and systematic and bibliometric reviews of the literature, in Web of Science, Scopus, and Publicações de Turismo databases, this study sought to identify scientific paper production related to the term "Scientific Tourism" until the present moment. A total of 32 articles were qualitatively and quantitatively analyzed, using Mendeley, Excel, QGIS and IRAMUTEQ software. Bibliometric laws were also verified. The main results point to a concentration of studies in 2016, and coming from European countries, especially from Poland. The articles were published in 23 journals from 13 countries, with emphasis on: Ido Movement for Culture, Annals of Tourism Research and Revista Brasileira de Ecoturismo. A total of 65 authors or co-authors were identified, the main ones being Polish: Wojciech J. Cynarski and Krzysztof Kubala. The categorization of themes around Scientific Tourism brings together discussions about scientific events and trips, nature tourism, education, geotourism, and socioeconomic development. Finally, there is a need for publications that deepen the theoretical discussion on Scientific Tourism. 
Palabras clave:

Turismo Científico;

Revisión sistemática;

Bibliometría.

Recebido em: 01/04/2020. Aprovado em: 14/05/2020. Editor:

Glauber Eduardo de Oliveira Santos



\begin{abstract}
Resumen
El objetivo de este trabajo es presentar una revisión sistemática de la literatura sobre Turismo Científico, en los contextos nacionales e internacionales. Por medio de investigaciones exploratorias y revisiones sistemáticas y bibliométricas de la literatura, en las bases de datos "Web of Science", "Scopus" y "Publicações de Turismo", este estudio buscó verificar la producción en formato de artículo científico relacionado con el palavra "Turismo Científico" hasta el momento presente. Un total de 32 artículos científicos fueron analizados cualitativa y cuantitativamente, utilizando el softwares Mendeley, Excel, QGIS e IRAMUTEQ. También se verificaron las leyes que rigen los estudios bibliométricos. Los principales resultados apuntan a una concentración de estudios en 2016 y procedentes de países europeos, especialmente de Polonia. Los artículos fueron publicados en 23 revistas de 13 países, con énfasis en: "Ido Movement for Culture", "Annals of Tourism Research" y "Revista Brasileira de Ecoturismo". Se identificaron 65 autores os coautores, los principales fueron los polacos Wojciech J. Cynarski y Krzysztof Kubala. La categorización de temas en torno al Turismo Científico reúne debates sobre eventos y viajes científicos, turismo de naturaleza, educación, geoturismo y desarrollo socioeconómico. Finalmente, existe la necesidad de publicaciones que profundicen la discusión teórica sobre Turismo Científico.
\end{abstract}

Como Citar: Conti, B. R.; Elicher, M.J.; Lavandoski, J. (2021). Revisão sistemática da literatura sobre Turismo Científico. Revista Brasileira de Pesquisa em Turismo, São Paulo, 15 (2), e-1981, maio/ago. http://dx.doi.org/10.7784/rbtur.v15i2.1981

\section{INTRODUÇÃO}

Este trabalho compõe um conjunto de pesquisas desenvolvidas em torno da temática do Turismo Científico (TC), visando aprofundar este campo de discussão do turismo, que pode ser entendido como uma área de atuação para pesquisas científicas e práticas turísticas. Nesse contexto, pretende-se, com este artigo, o aprofundamento do debate acadêmico sobre o TC.

Não há um consenso entre os pesquisadores e órgãos governamentais e não governamentais sobre o conceito de TC. Apesar da incipiente produção acadêmica, é possível identificar duas correntes: (1) aquela que o apresenta como um segmento de mercado, identificando-o, por vezes, como um subtipo de segmentos já consolidados (turismo cultural, turismo de intercâmbio, turismo de eventos, ecoturismo) (Bravo, Cuadrado, Belema e Sáenz 2017; Cynarski e Ďuriček, 2014; Margoni, 2015; Mieczkowski, 1995; Montaner Montejano, 2001; Revilla e Moure, 2017; Schlindwein, Akaki e Laganaro, 2011). E (2) outra corrente que o classifica como um dos paradigmas do turismo alternativo, sustentável (Benson, 2005; Corneloup, 2009; Laing, 2010). Assim, entende-se TC como o processo de elaboração de conhecimento científico a partir das experiências de viagem com o objetivo de realizar observações, coletar dados e informações para uso científico (Margoni, 2015), conforme será melhor discutido ao longo deste artigo.

O presente estudo busca mapear a produção científica sobre TC, por meio de uma revisão sistemática e bibliométrica da literatura. Assim, o objetivo deste trabalho é apresentar uma revisão sistemática da literatura sobre Turismo Científico, nos contextos nacional e internacional.

A revisão sistemática de literatura proposta inclui um estudo bibliométrico sobre a produção científica em TC, utilizando os softwares Mendeley (versão 1.19.5), Excel (versão 16.35), QGis (versão 3.8 Zanzibar) e Iramuteq (versão 0.7 alpha 2). A amostra final do estudo envolveu 32 artigos científicos que foram analisados quali-quantitativamente.

Este artigo está estruturado em cinco seções, incluindo esta Introdução. A seguir, na segunda, é apresentado o referencial teórico sobre TC, que permite identificar a evolução do tema desde o seu surgimento e as principais correntes teóricas sobre o assunto. A terceira seção apresenta o caminho metodológico seguido nesta pesquisa. A seção seguinte, "Resultados e Discussão", é dividida em duas partes, a primeira contém os dados resultantes da análise bibliométrica dos artigos selecionados para compor a amostra deste trabalho. A segunda parte, oferece uma análise da frequência das palavras no corpus textual e a conexão entre elas, a partir dos resumos dos trabalhos selecionados, além de uma categorização dos artigos por temas correlatos. Na quinta seção deste trabalho apresentam-se as Considerações Finais. 


\section{REFERENCIAL TEÓRICO}

A origem do Turismo Científico pode ser inicialmente identificada no final do século XIX, quando as expedições e estudos de campo começaram a ser utilizados como estratégias de pesquisa (Morse, 1997). Mas a discussão acadêmica sobre TC tem início na década de 1980 (Campos, 2018; Molokacova e Molokac, 2011), quando surge pela primeira vez em dois registros escritos, no ano de 1989. Estes artigos, de autoria de Jan Laarman e Richard Perdue, foram publicados nos seguintes periódicos: "Tourism Management", com o título "Tropical Science and Tourism: The case of OTS in Costa Rica", e "Annals of Tourism Research", com o título "Science Tourism in Costa Rica” (Campos, 2018; Laarman e Perdue, 1989).

Na literatura sobre TC, além de artigos científicos, é possível identificar livros que tratam da temática, como por exemplo a obra titulada "Scientific Tourism: Researchers as Travellers", com autoria de Susan Slocum, Carol Kline e Andrew Holden, publicada pela Routledge, em 2015. E mais recente, em 2019, a obra "Scientific Tourism: Some Places on the Way", de Peter Day.

0 termo vem sendo usado, na área de turismo, para caracterizar o trabalho realizado por exploradores para desbravar um determinado local (Margoni, 2015; Revilla e Moure, 2017). 0 surgimento do TC está ligado, ainda, à iniciativa de governos em parceria com a iniciativa privada em enviar pesquisadores a locais remotos para pesquisas e conhecimento de áreas inexploradas (Novelli, 2005). Como destaca Margoni (2015, p. 165), “...é a visitação de um destino turístico com o objetivo de realizar observações e coletar dados e informações que possam ser utilizados de forma científica".

No entanto, não há um consenso entre os pesquisadores e órgãos governamentais e não governamentais sobre o conceito de TC. Na literatura científica identifica-se, também, certa confusão entre os termos "turismo científico" e "ciência do turismo".

A "ciência do turismo" reúne a contribuição dos estudos científicos em todas as áreas do turismo para seu fortalecimento enquanto um campo da ciência (Margoni, 2015), com destaque para os estudos epistemológicos do turismo, fundamentais para o estabelecimento dos alicerces científicos deste campo de estudos. Como discutido por Moesch e Beni (2015), o conhecimento necessário à construção de uma "ciência do turismo" se utiliza de ferramentas com abordagens multi, inter e transdisciplinares, que viabilizam a contribuição dos diversos campos do saber para a construção do conhecimento em turismo. Já o "turismo científico" tem sido entendido como uma possibilidade prática voltada à produção da ciência, ou seja, é a realização da prática turística associada à produção do conhecimento científico, em diferentes áreas do saber.

A diferenciação desses dois termos conduz à seguinte reflexão, que pode explicar a confusão existente entre eles: ao realizar o TC, este se associa diretamente à produção de conhecimento científico, mas não, necessariamente, à produção de uma "ciência do turismo", ainda que o conhecimento "produzido" a partir das práticas de TC possa vir a contribuir para a evolução do turismo enquanto uma ciência.

Apesar da incipiente produção acadêmica sobre TC, é possível identificar duas correntes principais de discussão: (1) aquela que o apresenta como um segmento de mercado, identificando-o, por vezes, como um subtipo de segmentos já consolidados (turismo cultural, turismo de intercâmbio, turismo de eventos, ecoturismo); e (2) outra corrente que o classifica como um dos paradigmas do turismo alternativo, sustentável.

No que se refere ao entendimento do TC como segmento (1), Margoni (2015) discute que o turismo científico está sempre aliado a outros subtipos de turismo, pois parte da observação e análise de um tema, que pode ser um evento, a natureza, ou a cultura. A autora compreende ainda que o TC pode fazer parte do turismo de estudos e do turismo de intercâmbio, uma vez que o objetivo final está no aprimoramento que se alcançará pelo estudo de um tema específico. Nesse sentido, é uma forma do praticante se aprofundar em uma temática, mas que nem sempre apresenta a obrigatoriedade de publicação dos resultados observados com a prática deste turismo (Margoni, 2015).

Como subtipo do turismo cultural, o TC se apresenta como uma experiência em que o turista terá contato com a cultura do visitado, sendo que esta observação pode gerar a produção do conhecimento científico ou não. Enquanto subtipo do turismo de intercâmbio e/ou turismo educativo, o TC se caracteriza pelo 
aprimoramento profissional ou realização de programas específicos para aprendizado e treinamento. Como subtipo do ecoturismo, envolve a produção de conhecimento científico por meio de atividades como espeleoturismo, observação de aves (birdwatching), estudos do meio em unidades de conservação, turismo de aventura com dimensão científica, dentre outras. Já como subtipo do turismo de eventos, compreende a participação de estudantes e pesquisadores em eventos acadêmicos (Bravo et al., 2017; Cynarski e Ďuriček, 2014; Mieczkowski, 1995; Montaner Montejano, 2001; Revilla e Moure, 2017; Schlindwein, Akaki e Laganaro, 2011).

Especificamente para Montaner Montejano (2001), o termo TC está associado às visitas, estadas ou viagens a lugares onde a natureza oferece possibilidades para conhecer aspectos relacionados às ciências naturais. Nesta linha, Margoni (2015) compreende que o TC envolve o estudo e a análise de uma localidade ou de um objeto específico dessa área, tais como a fauna, a flora. Mas, destaca também, que este estudo pode estar vinculado à cultura de um local, o que implica no envolvimento da comunidade autóctone como essencial para o seu aprofundamento.

Logo, o TC desenvolve-se em áreas que, por motivos científicos, representam importantes testemunhos da cultura humana (da pré-história às épocas atual e futura). Filippova, Savvinova, Danilov, Gadal e KamičaitytéVirbašienéi (2017), ao estudarem as características ontológicas da paisagem cultural em Yakutia, na Rússia, identificaram três perfis de praticantes do TC, que são: (1) a pesquisa científica para os pesquisadores; (2) a formação prática e a educação de estudantes de instituições de ensino; (3) a história da pesquisa científica, recursos naturais únicos, patrimônio histórico e cultural para o público em geral.

Nesse sentido, Ereshko (2006 apud Filippova et al., 2017) subdivide o TC em dois estágios: (1) introdutório, quando objetos e amostras naturais e antropogênicas são mostrados aos turistas e são fornecidas explicações sobre elas pelos pesquisadores; e (2) participação subsidiária, quando os turistas participam de atividades científicas e afins como pessoal de apoio, como por exemplo em trabalhos de restauração e pesquisas de campo em cooperação com os cientistas; o que sugere a necessidade de aprofundamento da investigação de processos que envolvam a cocriação.

A outra corrente entende o TC como paradigma do turismo alternativo (2), em oposição ao turismo de massa (Benson, 2005; Laing, 2010), e como uma renovação das motivações turísticas (Corneloup, 2009). 0 turismo alternativo é caracterizado por ser de pequena escala de desenvolvimento, com alto nível de envolvimento local, minimização de impactos negativos sobre a base de recursos locais e as relações sociais existentes, maximização e retenção de resultados econômicos positivos para a economia local, envolvimento dos atores locais nos processos de tomada de decisão, e controle do processo de desenvolvimento do turismo sob responsabilidade da população local, ao invés dos investidores externos.

Nesse sentido, o TC se fundamenta nesta concepção de turismo, isto é, abandona os marcos do turismo moderno e industrial, e se alinha à concepção de sustentabilidade em seu sentido mais amplo (Benson, 2005). Esta corrente discute, portanto, que o TC proporciona o desenvolvimento de experiências imersivas, o aumento dos intercâmbios culturais, a promoção de práticas ecológicas, a valorização do território e uma investigação existencial e vivencial que proporciona novos sentidos à viagem (Corneloup, 2009).

A aproximação entre TC e turismo sustentável se apresenta enquanto um modelo inovador para o desenvolvimento do turismo. Como afirma Bourlon et al. (2011) esta pode ser uma forma de repensar o turismo em áreas de grande relevância socioambiental. Como exemplo, pode-se citar o Projeto Centro de Turismo Científico da Patagônia, que visa o desenvolvimento de capacidades locais, baseando-se no processo de fortalecimento tecnológico e de capacidades empresariais necessárias à operação de produtos para o TC, incluindo universidades e suas redes. A sustentabilidade do modelo proposto pelo Centro se baseia na vinculação entre agentes públicos, privados, empresariais e universitários. Este modelo permite investigações acadêmicas e, a partir delas, a criação de uma nova oferta turística mais cultural e formativa, baseada na interpretação científica.

Ainda sobre a corrente que entende o TC como um caminho para o turismo sustentável, Bosak (2015) descreve o processo de TC na Figura 1, a seguir. Este processo envolve a produção, disseminação e implementação do conhecimento, onde a ciência é o cerne da prática do TC. O conhecimento científico é, portanto, a chave para o desenvolvimento sustentável do turismo científico. 
Figura 1 - Processo de desenvolvimento do Turismo Científico

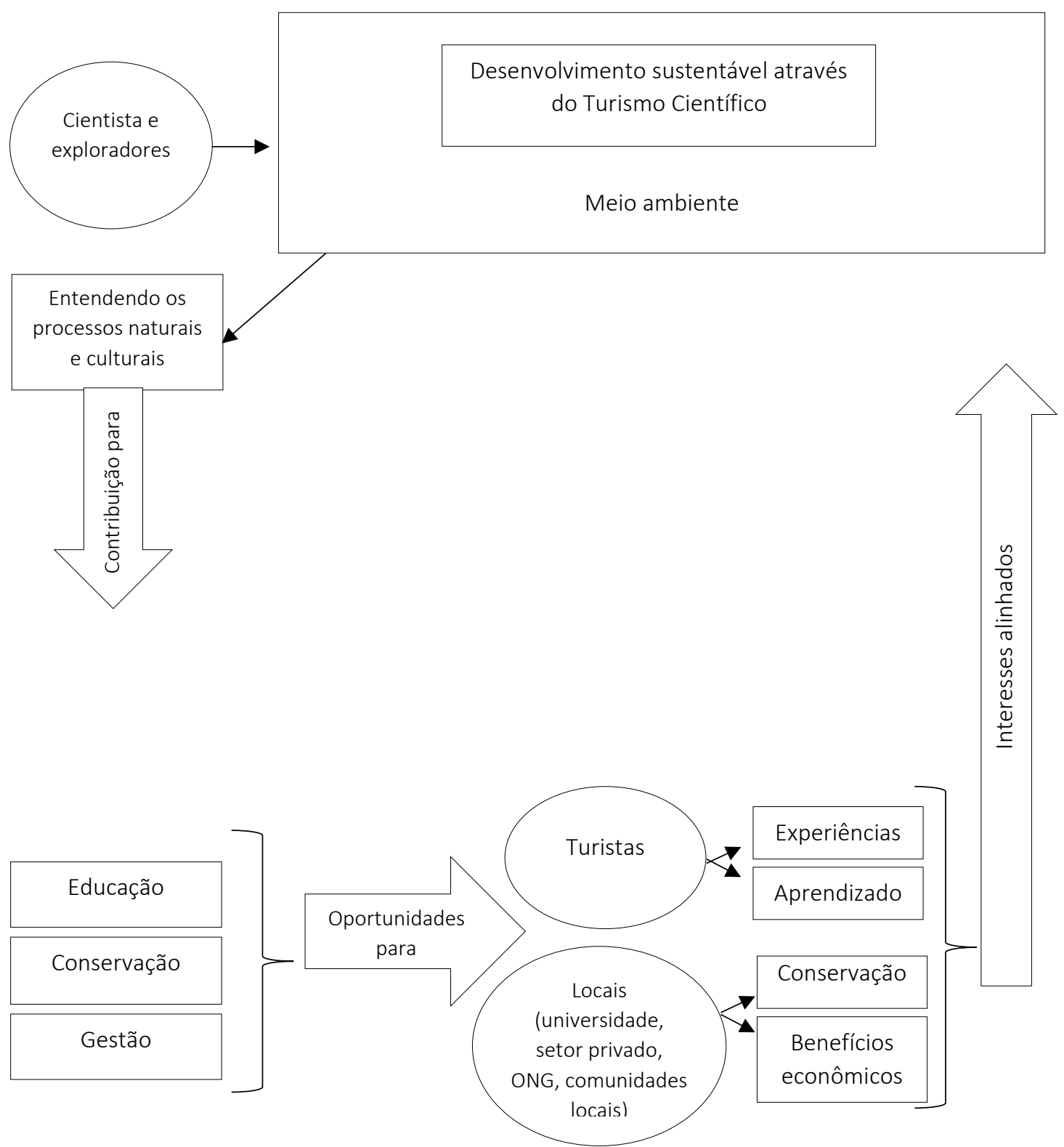

Fonte: Adaptado de Bosak (2015).

Conforme Figura 1, o primeiro passo do processo de desenvolvimento do TC é a inventariação científica que conduzirá à produção de conhecimento sobre o ambiente e seus processos. Este conhecimento será disseminado no âmbito da educação, conservação e gestão dos recursos para os turistas e os residentes. Para ambos, será uma oportunidade adicional de aprendizado e experiência, além de conservação dos recursos e das paisagens, fundamentais à produção do espaço para o turismo. Este caminho pode resultar em benefícios econômicos para os stakeholders ${ }^{1}$ envolvidos no turismo, com destaque para a comunidade local. O processo apresentado por Bosak (2015) avança para o alinhamento entre as necessidades dos turistas e dos moradores a fim de se alcançar o desenvolvimento sustentável do TC.

No que diz respeito à renovação das motivações turísticas, Molokacova e Molokac (2011) discutem que o público praticante do TC reúne pessoas que viajam por motivos relacionados à ciência, sendo divididos em: (1) amadores - o grupo de turistas que, em geral, busca um aprofundamento em um tema de interesse

10 termo compreende atores interessados em uma dada atividade. 
específico; (2) profissionais - pesquisadores que trabalham na área do turismo e realizam estudos a partir de uma base científica. Já para Revilla e Moure (2017), o público do TC se restringe a estudantes, professores e investigadores de diferentes disciplinas e áreas do conhecimento, com objetivo principal de ampliar e complementar seus conhecimentos.

Assim, o interesse ou a necessidade de realizar estudos e pesquisas é o elemento central do TC. Este se apresenta, portanto, como uma busca de sentido e de justificativa para o deslocamento turístico, isto é, viajar sim, mas de maneira útil (Bravo et al., 2017). Como exemplo, Revilla e Moure (2017) destacam os seguintes países receptores dos turistas que viajam motivados pelo conhecimento científico: Madagascar, África do Sul, China, Colômbia, Chile, Argentina, Brasil, já que estes possuem recursos naturais e culturais e lugares com alto conteúdo científico. Já os principais países emissores mapeados pelos autores são: Luxemburgo, Suécia, Noruega e Países Baixos.

A partir da breve análise das correntes de pensamento sobre o TC, anteriormente apresentadas, é possível perceber que ambas identificam um ponto chave em comum: a elaboração de conhecimento científico por meio das experiências de viagem - ainda que atendam aos interesses de um segmento comercial da prática turística (segmento de mercado) ou passem a considerar que a ciência é o cerne do processo, sendo o conhecimento científico a chave para o desenvolvimento sustentável do turismo nessas bases.

No item seguinte apresenta-se a metodologia empregada para a realização da pesquisa proposta.

\section{METODOLOGIA}

A metodologia deste trabalho compreende a realização de revisão sistemática de literatura sobre Turismo Científico, somada a uma revisão bibliométrica da produção acadêmica encontrada.

A revisão de literatura consiste no levantamento da produção científica disponível, "[...] objetivando selecionar tudo o que possa servir em sua pesquisa" (Laville e Dionne, 1999, p.112), a partir da compilação e entendimento dos conceitos anteriores à investigação, que já foram objeto de tratamento analítico em estudos precedentes. Assim, a revisão de literatura visa compreender as bases científicas e teóricas que compõem a construção do conhecimento (Panosso Netto e Nechar, 2014).

Já o objetivo das revisões sistemáticas é identificar eventuais lacunas de investigação na pesquisa existente (Busalim e Hussim, 2016), consistindo em um método de identificação, avaliação e interpretação de um objeto específico (Sonego e Echeveste, 2016). Uma das principais características deste tipo de revisão é a abrangência na coleta de dados e a divulgação dos critérios de pesquisa adotados, a fim de permitir sua replicação (Galvão e Pereira, 2014).

Sua realização é composta por seis fases: a) Elaboração da pergunta norteadora, fase em que se determina quais serão os estudos incluídos, os meios adotados para a identificação e as informações coletadas de cada estudo selecionado. Deve ser elaborada de forma clara e específica, incluindo teorias e raciocínios já aprendidos pelo pesquisador. b) Busca ou amostragem na literatura, nesta fase a busca na base de dados deve ser ampla e diversificada. Os critérios de amostragem precisam garantir a representatividade da amostra, sendo importantes indicadores da confiabilidade e da fidedignidade dos resultados. 0 ideal é incluir todos os estudos encontrados ou a sua seleção randomizada; ou ainda, é possível trabalhar com a definição de critérios claros de inclusão e exclusão de artigos. c) Coleta de dados, fase em que os dados são extraídos dos artigos selecionados. Estes dados devem incluir o tamanho da amostra, metodologias utilizadas, conceitos basilares, mensuração de variáveis, dentre outros. d) Análise crítica dos estudos selecionados, levando-se em consideração a experiência do pesquisador. e) Discussão dos resultados, com síntese, interpretação e eventual comparação entre os dados evidenciados na análise dos artigos. f) Apresentação clara e completa da revisão sistemática, permitindo a avaliação crítica dos resultados (Ganong, 1987; Souza, Silva e Carvalho, 2010).

A revisão sistemática oferece, portanto, um resumo da literatura existente somado à interpretação crítica do diagnóstico realizado, resultando em avanços teóricos relacionados ao fenômeno em questão.

A associação da revisão sistemática da literatura à uma revisão bibliométrica, reunindo aspectos qualitativos e quantitativos, permitirá a identificação do panorama buscado (Albach, 2015). A revisão bibliométrica ou 
bibliometria consiste, assim, na aplicação de métodos estatísticos e matemáticos na análise da produção científica, cujos objetivos são: mapear a produção de artigos de um campo do saber, as comunidades acadêmicas dedicadas à pesquisa em questão, as redes de pesquisadores que analisam o assunto, a produtividade dos periódicos, dentre outros (Chueke e Amatucci, 2015).

Nesse sentido, o método bibliométrico pode colaborar na sistematização da produção científica em um determinado campo do saber e apontar novas áreas de investigação (Chueke e Amatucci, 2015). Para realização de um estudo bibliométrico é indicado que o pesquisador atenda às Leis que regem esse modelo de estudo, conforme Tabela 1:

\begin{tabular}{llll}
\multicolumn{2}{l}{ Tabela 1 - Leis que regem os estudos bibliométricos } & & \\
\hline Leis & Medida & Critério & Objetivo principal \\
\hline Lei de Bradford & Grau de atração do periódico & Reputação do periódico & $\begin{array}{l}\text { Identificar os periódicos mais relevantes e que } \\
\text { dão maior vazão a um tema em específico }\end{array}$ \\
Lei de Zipf & Frequência de palavras-chave & Lista ordenada de temas & $\begin{array}{l}\text { Estimar os temas mais recorrentes relaciona- } \\
\text { dos a um campo de conhecimento }\end{array}$ \\
Lei de Lotka & Produtividade do autor & Tamanho, frequência & $\begin{array}{l}\text { Levantar o impacto da produção de um autor } \\
\text { numa área de conhecimento }\end{array}$
\end{tabular}

Fonte: Chueke e Amatucci (2015, p.3).

Diante do exposto, este trabalho pretende apresentar uma revisão sistemática e bibliométrica da literatura sobre Turismo Científico. A seguir são descritos os procedimentos metodológicos utilizados.

\subsection{Procedimentos metodológicos}

Os procedimentos metodológicos seguiram as seguintes etapas: a) Seleção das bases de busca da produção científica; b) Definição das palavras-chave de busca; c) Seleção dos parâmetros de busca utilizados em cada base; d) Seleção das produções científicas identificadas nas bases de busca; e) Identificação das publicações no formato de artigo científico; f) Análise quali-quantitativa dos resultados.

Para a busca da produção científica (a) foram selecionadas as bases "Web of Science" e "Scopus", as quais reúnem periódicos renomados no idioma inglês, variedade de filtros e inclusão de pesquisadores da área do Turismo; e a plataforma "Publicações de Turismo2", por privilegiar artigos iberoamericanos, além de disponibilizar artigos completos de acesso aberto.

A opção pelo termo de busca (b) utilizado foi a palavra-chave "turismo científico" nas suas variações idiomáticas "science tourism" e "scientific tourism" em inglês; e "turismo científico" em espanhol (o mesmo que em português). Tal escolha se deu em razão da realização de um pré-estudo com o auxílio do operador booleano "and" relacionando as palavras "turismo", "ciência”, "científico", de modo a cruzar os termos entre si, conforme sugere Chueke e Amatucci (2015).

A verificação primária evidenciou que a associação entre "turismo" e "ciência" ou "turismo" e "científico" não resultou em produções que de fato tratavam do tema Turismo Científico. A partir da combinação das palavras "turismo" e "ciência", por exemplo, muitos dos artigos identificados tratavam, na verdade, de uma discussão sobre a "ciência do turismo", como já explicado anteriormente. Assim, optou-se pela utilização de uma única palavra-chave, sendo esta: “turismo científico". Vale destacar, ainda, que este pré-estudo apontou para a utilização de diferentes termos em inglês, mas que traduzem um mesmo significado, a saber: "science tourism" e "scientific tourism". Além disso, foi possível observar que as buscas dos termos nos idiomas português e espanhol não apresentaram diferenciação nos resultados, dado que a grafia nas duas línguas é a mesma.

A busca (c) foi realizada em setembro de 2019, contemplando todos os anos de produção até aquele momento. Para a base "Web of Science" foi utilizado o parâmetro de busca "tópico", que compreende

\footnotetext{
2 Website desenvolvido pelo Programa de Graduação em Turismo da Universidade de São Paulo (PPGTUR) para oferecer acesso gratuito aos periódicos de turismo.
} 
"título", "resumo", "palavras-chave de autor" e "keywords plus ${ }^{\circledR}$ ". Na base "Scopus" foram utilizados os parâmetros de busca "article title", "abstract", "keywords", "articles". Para estas bases, as buscas foram realizadas nos idiomas "inglês", "português" e "espanhol". Todos os arquivos foram exportados em formato Bibitex considerando as informações relativas a autor, título, fonte e resumo. Para a plataforma "Publicações de Turismo" foi utilizado o parâmetro de busca "todos os campos", que compreende "título", "autor", "palavras-chave" e "resumo". Posteriormente, por meio do software Mendeley (versão 1.19.5), foram selecionados e organizados os artigos que compõem a amostra deste estudo. Além disso, o software possibilitou a leitura dos seus respectivos resumos e sua categorização. Os artigos da base "Publicações de Turismo” foram salvos em “.pdf” e inseridos manualmente no Mendeley.

A busca inicial (d), a partir dos critérios anteriormente apresentados, resultou em um total de 96 publicações, mas, excluídas as duplicatas, restaram 75. Destas publicações (e) foram identificados 15 trabalhos publicados em anais de eventos e um book review, que foram excluídos da amostra por não atenderem ao critério adotado: "publicações no formato de artigo científico". Assim, resultaram 59 artigos científicos (Figura 2).

Após leitura e avaliação dos títulos e resumos (f), a fim de verificar se as publicações tinham por objetivo central tratar o tema do Turismo Científico, foram recuperados 32 artigos científicos. Vale destacar que esta análise excluiu da amostra um total de 27 artigos que não apresentavam uma discussão teórica ou uma proposta de aplicação ou planejamento do TC. Estes artigos, em sua maioria, apresentavam um dos termos de busca apenas em suas palavras-chave, sendo que este termo não foi resgatado no título ou resumo do artigo. Outros indicavam, ao final do resumo, o TC como uma potencialidade para um determinado local, sem, contudo, desenvolver qualquer análise ou proposição nesse sentido. Por fim, outros artigos excluídos tratavam o TC na perspectiva da ciência do turismo (epistemologia do turismo).

A Figura 2, a seguir, apresenta a proposta final que será tratada de forma quali-quantitativa na seção 3 deste trabalho. Importa destacar que optou-se por realizar uma análise de natureza quali-quantitativa em função do tamanho da amostra ser reduzido, seguindo, portanto, as sugestões de Chueke e Amatucci (2015).

Figura 2 - Procedimento de coleta de dados e definição da amostra do estudo


dados da pesquisa (2019).

Para a análise da amostra final $(n=32)$ foram utilizados os softwares Excel (versão 16.35), QGis (versão 3.8 Zanzibar) e Iramuteq (versão 0.7 alpha 2). 0 software Excel permitiu analisar quantitativamente os artigos da amostra e gerar figuras e tabelas que apresentam a linha do tempo das publicações, identificam os autores e suas instituições de filiação, os periódicos mais relevantes, dentre outros dados. O software QGis permitiu elaborar um mapa com a localização das áreas de interesse dos estudos de caso que compõem a 
amostra desta pesquisa (ver seção 4.1). E o software Iramuteq, a partir da análise qualitativa do corpus textual (resumos dos artigos), permitiu gerar análises de similitude entre esses corpus e nuvem de palavras (ver seção 4.2).

\section{RESULTADOS E DISCUSSÃO}

\subsection{Análise descritiva}

Nesta seção serão apresentados e analisados, por meio do software Excel, os dados resultantes da revisão da literatura abordando uma análise bibliométrica dos artigos selecionados para compor a amostra deste trabalho, tais como: 1) Evolução do número de publicações ao longo dos anos; 2) Principais autores e impacto de sua produção numa dada área de conhecimento; 3) Países em que o tema é mais popular; 4) Periódicos mais relevantes que abordam a temática em questão.

A evolução das publicações sobre TC pode ser visualizada na Figura 3, a seguir:

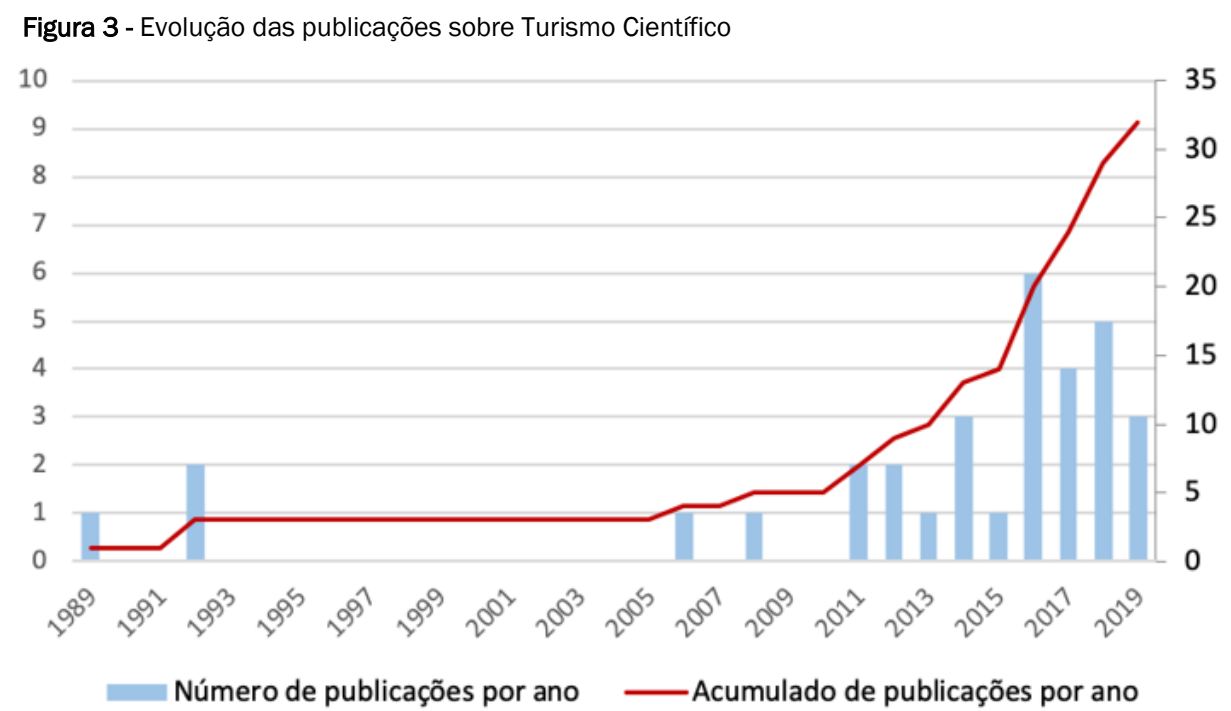

Fonte: Elaboração própria a partir do software Excel com os dados da pesquisa (2019).

A partir da análise dos 32 artigos recuperados, é possível identificar que o primeiro artigo sobre TC foi publicado no ano de 1989, com o título "Science Tourism in Costa Rica", no periódico "Annals of Tourism Research". 0 artigo tem autoria de Jan Laarman e Richard Perdue, ambos membros do corpo docente da "North Carolina State University". O estudo analisa estudantes, pesquisadores e professores que realizam treinamento e pesquisa na Costa Rica e considera o Turismo Científico um subcomponente do turismo natural.

É possível perceber, na figura anterior, que o ano de 2016 foi o mais relevante para as publicações sobre TC, a partir de quando se identifica um aumento no número de publicação, sendo o artigo mais recente datado de 2019. É possível identificar que os autores poloneses ampliam suas publicações sobre TC no período de 2014 a 2018, com destaque para os anos 2016 e 2017, o que pode ser uma das justificativas da ampliação do número de publicações nos últimos anos.

Além disso, é possível justificar o crescimento da importância do tema devido à ampliação de diversas estratégias a nível mundial que vêm sendo recentemente adotadas para a popularização da ciência. Para o caso do Brasil pode-se citar as ações e iniciativas do Ministério da Ciência, Tecnologia, Inovações e Comunicações para a popularização da ciência e tecnologia e para a divulgação científica com o objetivo de contribuir para a promoção e apropriação do conhecimento científico-tecnológico pela população em geral, sendo que o TC tem sido considerado como uma dessas iniciativas (MCTIC, 2020). 
Vale destacar também que a popularização da ciência se encontra dentre os 17 Objetivos de Desenvolvimento Sustentável estabelecidos pelas Nações Unidas (Meta 9.5) (ONU, 2015), que trabalha no sentido de fortalecer, até 2030, a pesquisa científica; melhorar as capacidades tecnológicas de setores industriais em todos os países, particularmente os países em desenvolvimento; e incentivar a inovação e os gastos público e privado em pesquisa e desenvolvimento. 0 turismo passa a ser considerado, também, como um caminho para a disseminação da ciência entre os povos.

Outra possível explicação para o aumento das publicações sobre o tema, no ano de 2016, pode estar relacionada ao lançamento do livro "Scientific Tourism: Researchers as Travellers", de autoria de Susan Slocum, Carol Kline e Andrew Holden, publicado no ano anterior, que projeta o debate sobre Turismo Científico internacionalmente.

Tabela 2 - Periódicos dos trabalhos analisados

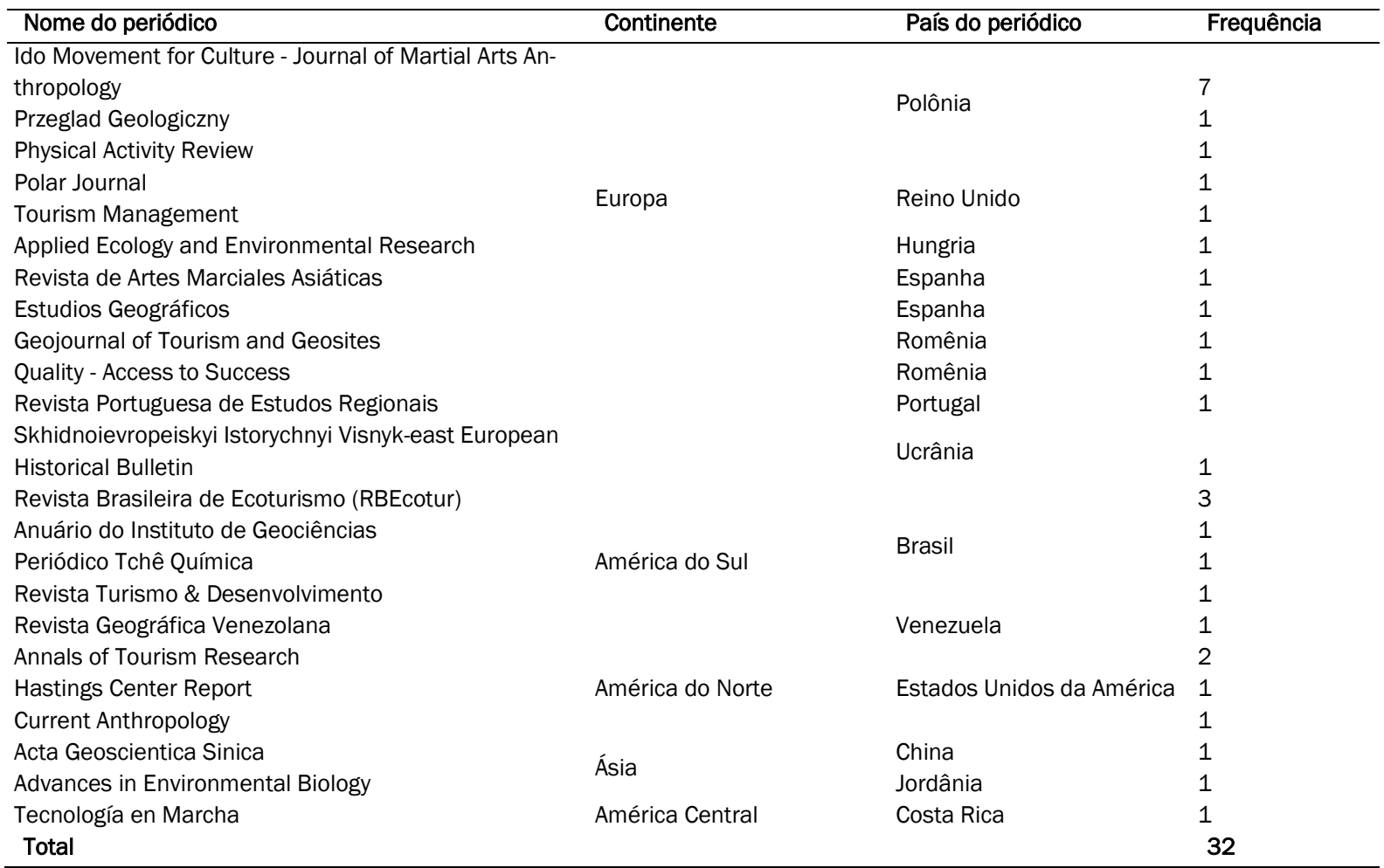

Fonte: Elaboração própria a partir do software Excel com os dados da pesquisa (2019).

Sobre os periódicos, identificou-se que os artigos foram publicados em 23 periódicos de 13 países diferentes. As publicações mais recorrentes se concentram em 3 periódicos: "Ido Movement for Culture Journal of Martial Arts Anthropology", "Annals of Tourism Research" e "Revista Brasileira de Ecoturismo (RBEcotur)", respectivamente (Tabela 2).

É interessante observar que o periódico com maior número de artigos sobre TC é oriundo da Polônia, que publica artigos científicos originais sobre vários aspectos, em particular sobre as artes marciais em seus aspectos sociológico e antropológico. Vale destacar que os artigos sobre TC publicados neste periódico caracterizam os eventos realizados em torno da discussão das artes marciais, em sua maioria, como sendo de Turismo Científico.

O segundo periódico de maior relevância para o TC é também um dos principais periódicos internacionais da área de Turismo. 0 “Annals of Tourism Research”, filiado nos Estados Unidos da América, é uma revista de ciências sociais com foco nas perspectivas acadêmicas do turismo. Enquanto se esforça para um equilíbrio entre teoria e aplicação, é finalmente dedicado ao desenvolvimento de construções teóricas. Já o terceiro periódico no ranking, de origem brasileira, é voltado à discussão teórica e de estudos de caso sobre ecoturismo. Percebe-se que os artigos sobre TC publicados na Revista Brasileira de Ecoturismo o discutem em associação às viagens de pesquisadores às áreas naturais protegidas, ao turismo de observação de aves, ao geoturismo, dentre outras perspectivas de pesquisa ou educação em ambientes naturais. 
$\mathrm{Na}$ Tabela 3, a seguir, os três periódicos com mais publicações sobre TC são retratados em relação à área/categoria, idioma de publicação, ISSN e diferentes métricas de citação como "H Index", "RG Journal Impact" e "Qualis Capes". A respeito das métricas, o periódico "Annals of Tourism Research" possui a melhor pontuação em relação aos rankings analisados. Dentre estes três periódicos, o "Ido Movement for Culture Journal of Martial Arts Anthropology" é o único que não pertence à área científica do Turismo, mas sim, à Educação Física.

Tabela 3 - Periódicos com mais concentração de publicações sobre Turismo Científico

\begin{tabular}{|c|c|c|c|c|c|c|}
\hline Periódico & Área & Idioma (a) & ISSN (a) & H Index (b) & $\begin{array}{l}\text { RG Journal } \\
\text { Impact (c) }\end{array}$ & Qualis Capes (2013-2016) (d) \\
\hline $\begin{array}{l}\text { Ido Movement for } \\
\text { Culture - Journal } \\
\text { of Martial Arts An- } \\
\text { thropology }\end{array}$ & $\begin{array}{l}\text { Sociology of Culture; Psycho- } \\
\text { physical Culture; Anthropology of } \\
\text { Martial Arts, Combat Sports, Cul- } \\
\text { tural Tourism (a) }\end{array}$ & $\begin{array}{l}\text { Inglês, } \\
\text { polonês }\end{array}$ & $\begin{array}{l}2084- \\
3763 \\
2082- \\
7571\end{array}$ & 7 (2018) & $\begin{array}{l}1.90 \\
(2018 / 2019)\end{array}$ & B1 - Área Educação Física \\
\hline $\begin{array}{l}\text { Annals of Tourism } \\
\text { Research }\end{array}$ & $\begin{array}{l}\text { Business; Management and Ac- } \\
\text { counting; Tourism, Leisure and } \\
\text { Hospitality Management; Social } \\
\text { Sciences Development (b) }\end{array}$ & Inglês & $\begin{array}{l}0160- \\
7383\end{array}$ & $\begin{array}{l}144 \\
(2018)\end{array}$ & $\begin{array}{l}2.50 \\
(2018 / 2019)\end{array}$ & $\begin{array}{l}\text { A1 - Área Administração Pú- } \\
\text { blica e de Empresas, Ciências } \\
\text { Contábeis e Turismo } \\
\text { A2 - Área Interdisciplinar }\end{array}$ \\
\hline $\begin{array}{l}\text { Revista Brasileira } \\
\text { de Ecoturismo } \\
\text { (RBEcotur) }\end{array}$ & $\begin{array}{l}\text { Ecoturismo e Educação Ambien- } \\
\text { tal; Planejamento e Gestão do } \\
\text { Ecoturismo; Manejo e Conserva- } \\
\text { ção dos recursos naturais atra- } \\
\text { vés do Turismo Sustentável; En- } \\
\text { sino, Pesquisa e Extensão em } \\
\text { Ecoturismo; Ecoturismo de Base } \\
\text { Comunitária (a) }\end{array}$ & $\begin{array}{l}\text { Português } \\
\text { espanhol, } \\
\text { inglês }\end{array}$ & $\begin{array}{l}1983- \\
9391\end{array}$ & 0 & 0 & $\begin{array}{l}\text { B3 - Área Administração Pú- } \\
\text { blica e de Empresas, Ciências } \\
\text { Contábeis e Turismo } \\
\text { B3 - Área Interdisciplinar (e) }\end{array}$ \\
\hline
\end{tabular}

(a) Dados retirados do website do periódico; (b) https://www.scimagojr.com; (c) https://www.researchgate.net/; (d) https://sucupira.capes.gov.br/; (e) Esta revista possui 21 pontuações diferentes (variando de B1 a C) para diferentes áreas.

Fonte: Elaboração própria a partir dos softwares Mendeley e Excel com os dados da pesquisa (2019).

Confrontando os resultados acima com a Lei de Bradford (Tabela 1), que apoia-se no critério de reputação dos periódicos para identificar os mais relevantes e que dão maior vazão a um tema em específico, têm-se as seguintes conclusões: o periódico mais relevante que aborda assuntos do Turismo Científico é o "Annals of Tourism Research" para as áreas de "Administração Pública e de Empresas, Ciências Contábeis e Turismo" e "Interdisciplinar". Por outro lado, para a área de "Educação Física”, o periódico de maior destaque é o "Ido Movement for Culture - Journal of Martial Arts Anthropology". O critério utilizado para conferir a relevância dos periódicos foi a classificação da produção científica Qualis/CAPES³. Para os periódicos internacionais foi utilizada também a referência do "Índice H" ( $H$ Index) disponível na plataforma "Scimago Journal \& Country Rank"4, desenvolvida pela Scopus.

Analisando a autoria dos artigos, identifica-se um total de 65 autores ou coautores diferentes. A maioria dos artigos foi escrita em coautoria, sendo que apenas 9 possuem somente um autor. Dois autores destacamse em função da autoria ou coautoria em mais de um artigo: Wojciech J. Cynarski e Krzysztof Kubala. Wojciech J. Cynarski tem autoria em 8 trabalhos (sendo 6 como primeiro autor e 2 como segundo autor). É professor na Faculdade de Educação Física, Departamento de Fundamentos Culturais da Educação Física, Turismo e Recreação, da University of Rzeszów (Polônia), editor-chefe do periódico “Ido Movement for Culture - Journal of Martial Arts Anthropology", e tem vínculo com a "International Martial Arts and Combat Sports Scientific Society (IMACSSS)". Desenvolve pesquisas nas seguintes áreas: sociologia do esporte e sociologia do tempo livre, sociologia e antropologia da cultura, turismo e artes marciais, e ciência das culturas militares. Já Krzysztof Kubala tem autoria em 2 trabalhos (sendo 1 como primeiro autor e 1 como segundo autor). Kubala é também vinculado à University of Rzeszów e à "International Martial Arts and Combat Sports Scientific Society (IMACSSS)”, Polônia. Estes autores publicaram conjuntamente em dois artigos.

Assim, destaca-se que o cálculo da Lei de Lotka, que aponta a necessidade de mapear os autores que possuem maior produção e, portanto, grande valor em um campo do conhecimento, não se mostrou

\footnotetext{
3 Sistema brasileiro de avaliação de periódicos, mantido pela Coordenação de Aperfeiçoamento de Pessoal de Nível Superior (CAPES), que relaciona e classifica os veículos utilizados para a divulgação da produção intelectual dos programas de pós-graduação "stricto sensu". Disponível em: https://sucupira.capes.gov.br/sucupira/public/consultas/coleta/veiculoPublicacaoQualis/listaConsultaGeralPeriodicos.jsf. Acesso em 28 abr. 2020.

4 Disponivel em: https://www.scimagojr.com/index.php. Acesso em 28 abr. 2020.
} 
relevante, pois foram mapeadas apenas duas repetições de autor: Wojciech J. Cynarski e Krzysztof Kubala. Ao analisar o "Índice $\mathrm{H}^{5}$ dos pesquisadores pela plataforma Scopus, encontra-se, respectivamente, Índice $\mathrm{H}=9$ e Îndice $\mathrm{H}=2$.

\begin{tabular}{ll} 
Tabela 4 - País dos autores com publicações sobre Turismo Científico \\
\hline País do autor & Frequência \\
\hline Brasil & 16 \\
Polônia & 8 \\
China & 6 \\
Canadá & 2 \\
Irã & 4 \\
Estados Unidos da América & 4 \\
Geórgia & 3 \\
Egito & 2 \\
Nova Zelândia & 2 \\
Portugal & 2 \\
Espanha & 2 \\
Ucrânia & 2 \\
Costa Rica & 1 \\
Inglaterra & 1 \\
Alemanha & 1 \\
México & 1 \\
Escócia & 1 \\
Não identificado & 7 \\
Total & 65 \\
Fonte: Elaboração própria a partir do software Excel com os dados da pesquisa (2019).
\end{tabular}

Em relação ao país dos autores que publicaram sobre TC, a Tabela 4 mostra um total de 65 nacionalidades, com maior concentração do Brasil, com 16 autores (24,6\%); da Polônia, com 8 autores (12,3\%); e da China, com 4 autores $(9,2 \%)$. Uma explicação para este grande número de autores brasileiros é a existência de vários artigos em coautoria e, especificamente, um trabalho com 6 autores. Por outro lado, a menor quantidade de autores poloneses é explicada em função de muitos trabalhos serem escritos por 1 ou até 2 autores. Cabe ressaltar que não foi possível identificar a nacionalidade de 7 autores (10,8\%). Mas, evidenciou-se que os autores são, sobretudo, do continente Europeu (30,7\%).

A partir da análise quantitativa, foi possível ainda mapear as áreas de interesse dos estudos de caso tratados nos artigos que compõem a amostra desta pesquisa, com o objetivo de identificar algumas das principais práticas relativas ao tema em questão. A Figura 4, a seguir, evidencia a distribuição geográfica desses estudos de caso.

Dos 32 artigos é possível identificar que 11 estudos de caso se concentram no continente americano, 12 na Ásia, 10 na Europa, 1 na Oceania e 1 no continente africano. Vale ressaltar, no entanto, que há estudos que contam com mais de um lugar de interesse, ou seja, trabalham de forma comparativa acontecimentos em mais de um país ou cidade, localizados em diferentes continentes, o que resulta em uma soma de estudos de caso maior que a quantidade de artigos da amostra.

Os países mais estudados de forma empírica foram China, Rússia, Costa Rica, Japão, Coreia do Sul e Brasil, totalizando 17 estudos, com destaque para o Brasil, abordado em 6 artigos da amostra. Desses 6 artigos, um tem o país como referência de estudo (25A), os outros tratam especificamente do Parque Geológico do Araripe, no Ceará (7); da Ilha do Cardoso, em Cananéia, São Paulo (28); da Floresta Nacional de Caxiuanã, no Pará (29); da Área de Proteção Delta do Parnaíba, no Piauí (30); e da Área de Relevante Interesse Ecológico Mata da Bica, no município de Portalegre, Rio Grande do Norte (31).

Para o caso da Antártica, há dois artigos que abordam este continente (15 e 17). Chama atenção a grande quantidade de publicações dos autores poloneses, identificada na Tabela 4, e que não aparece representada

5 O “Índice H” mensura o impacto da produção científica de pesquisadores. Disponível em: https://www.scopus.com/. Acesso em 28 abr. 2020. 
na Figura 4. Isso pode ser explicado em função dos estudos desenvolvidos pelos poloneses envolverem análises sobre eventos esportivos realizados em outros países, que não a Polônia.

Figura 4 - Localização das áreas de interesse dos estudos sobre Turismo Científico*

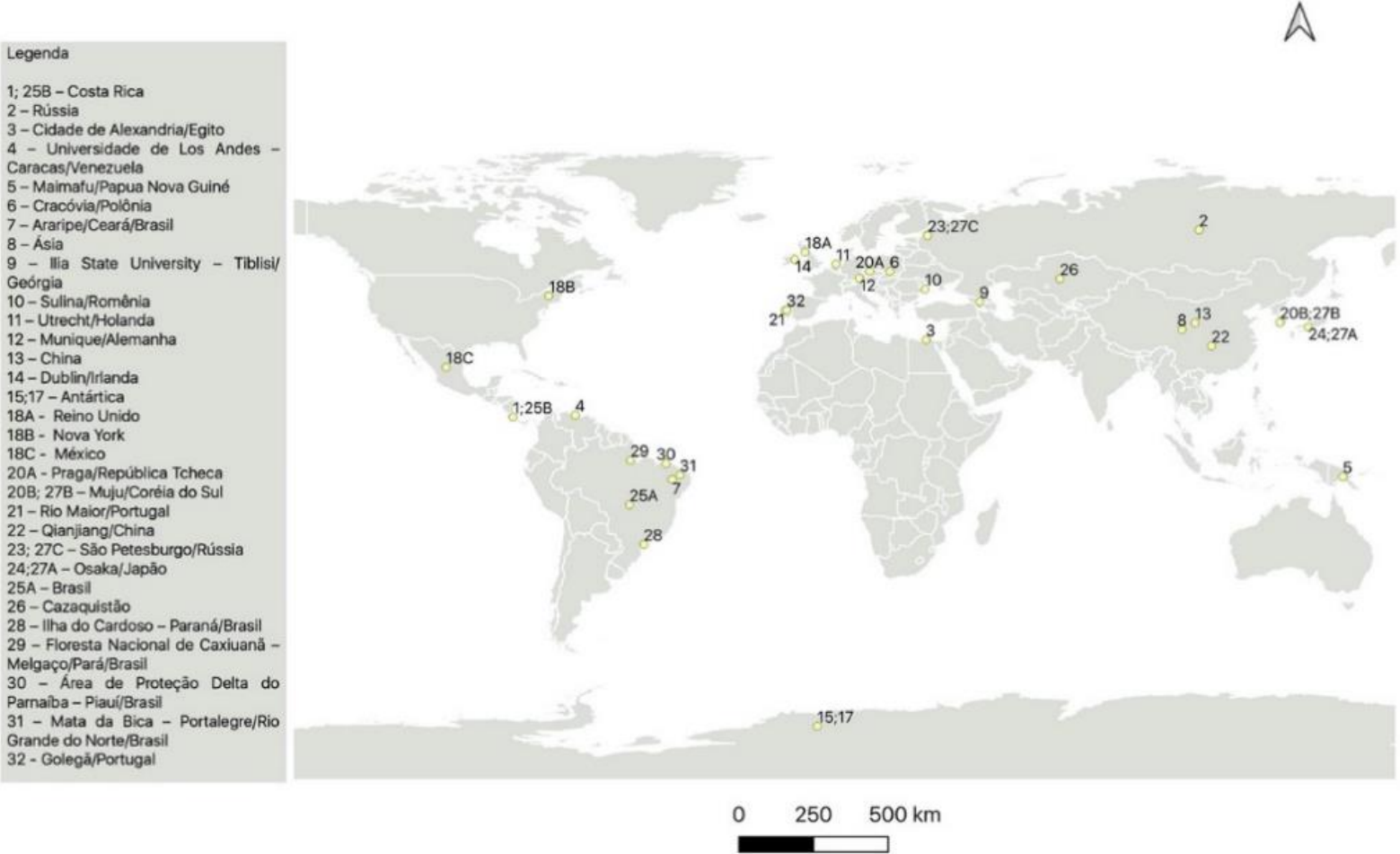

*Obs: Os artigos da amostra foram numerados e estão identificados na legenda e no mapa. Contudo, houve a necessidade de incluir letras para a organização da legenda: os artigos foram nomeados com A, B, C quando apresentavam, em seus estudos de caso, mais de uma referência geográfica (exemplo do artigo 18 que trabalha com três diferentes áreas geográficas de investigação: Reino Unido, Nova York e México, identificadas no mapa como 18A, 18B e 18C). Quando as pesquisas apontavam um país como área de abrangência do estudo, optou-se por usar como marco a sua capital, o que ocorreu nos artigos 1, 13 e 25A e B (Costa Rica, Brasil e China). Quando o estudo abordava um continente, optou-se por marcá-lo em um ponto central do mesmo (artigo 8). Quando há áreas específicas dentro de um mesmo país, estas foram marcadas de maneira individual, a exemplo do Brasil e seus seis estudos de caso (7, $25 \mathrm{~A}, 28,29,30$ e 31). 0 artigo 16 não foi marcado por se tratar de um estudo teórico e o 19 não aborda estudo com um recorte específico.

Fonte: Elaboração própria a partir do software QGis com os dados da pesquisa (2019).

Partindo para a análise da Lei de Zipf (Tabela 1), medida pela frequência das palavras-chave presentes nos artigos científicos, foi possivel obter o seguinte resultado: as palavras mais recorrentes relacionadas ao campo em análise são "turismo científico", "conferência", "artes marciais", "turismo", "ecoturismo", "esportes de combate". A Figura 5 apresenta as palavras-chave, com os termos em inglês, que se repetem mais de duas vezes nos artigos científicos. 
Figura 5 - Frequência das palavras-chave nos artigos científicos

Frequência das palavras-chave nos artigos científicos



Fonte: Elaboração própria a partir do software Excel com os dados da pesquisa (2019).

É possível notar também o uso de palavras com sentidos semelhantes que, se agrupadas, evidenciam ainda mais a importância desses termos, tais como: "conference" e "scientific conferences", e "martial arts" e "martial arts tourism".

A seção a seguir apresenta as análises qualitativas realizadas a partir dos resumos dos artigos científicos, isto é, as análises do corpus textual.

\subsection{Análises do corpus textual}

Diante do objetivo deste trabalho de mapear a produção científica sobre TC, as análises textuais realizadas, a partir do uso do software Iramuteq, foram desenvolvidas considerando os resumos dos artigos ( $n=32)$, que representam o corpus textual. As análises compreendem a frequência das palavras e a conexão entre elas (Salvati, 2017).

A seguir estão apresentadas a nuvem de palavras (Figura 6) e a análise de similitude (Figuras 7 e 8). Enquanto a primeira leva em consideração todas as palavras presentes nos resumos ( $n=32)$, a segunda análise considera, para a mesma amostragem, os termos com frequência igual ou superior a 10 (Figura 7) e os termos com frequência igual ou superior a 5 (Figura 8).

A nuvem de palavras apresenta os termos no idioma inglês, como apresentado nos resumos dos artigos. Os termos que apresentam maior frequência nos resumos, ou seja, os mais utilizados, são apresentados a seguir, conjuntamente com a quantidade de citação: “turismo" $(n=163)$, "pesquisa” ( $n=39)$, “estudo" $(n=38)$, "desenvolvimento“ $(n=33)$, “conferência” ( $n=33)$, “arte” $(n=33)$, “área” $(n=32)$, “internacional” $(n=26)$, "ciência" ( $n=21)$, "evento" ( $n=21)$, "método" ( $n=20)$, "participante" ( $n=19)$, “comunidade" ( $n=19)$, "esporte" $(n=18)$, "universidade" ( $n=16)$, "pesquisador" $(n=16)$. É possível verificar que o tamanho da fonte de cada termo é diretamente proporcional à sua respectiva frequência nos resumos analisados.

Além do termo "turismo", vale destacar que a palavra "científico" também foi utilizada de maneira recorrente ( $n=95)$, porém, em função de uma limitação no vocabulário do software, ela não é reconhecida em seu banco de palavras. Por este motivo, não está evidenciada na Figura 6, assim como outras palavras que o software não identificou, tais como: "marciais" $(n=32)$, "cultural" $(n=17)$, “ecoturismo" $(n=14)$, "ambiente" $(n=12)$, "geológico" ( $n=11)$, "geoparque" $(n=10)$, dentre outras. A expressão "turismo científico" é, portanto, a mais recorrente na análise, aparecendo em maior quantidade tanto no corpo dos resumos como nas palavraschave dos artigos. 
Figura 6 - Nuvem de palavras sobre Turismo Científico



Fonte: Elaboração própria a partir do software Iramuteq com base nos resultados da pesquisa (2019).

Apesar da impossibilidade de visualização do termo "científico", outros termos relacionados podem ser identificados, como "ciência”, "estudo", “pesquisa”, "método", “universidade”, o que evidencia a ligação do Turismo Científico com a realização de pesquisas científicas, e não simplesmente com a prática de atividades de lazer fora do lugar habitual de residência e trabalho dos pesquisadores-viajantes. Ou seja, o TC não parece se comportar apenas como um segmento de mercado. Os termos "conferência" e "evento" corroboram tal análise, uma vez que diversos artigos têm como foco a discussão da importância da realização de um determinado evento científico (os eventos relacionados às artes marciais e a outros esportes têm relevância nos artigos de TC, como já discutido anteriormente), ou ainda, relatam as viagens de professores e estudantes a esses eventos e a diversos centros de pesquisa ou áreas de grande valor científico, com destaque para as áreas naturais. Nesse sentido, se destacam as palavras "natural", "meio ambiente", “natureza”, “parque”, “observação”, “conhecimento”, ainda que em menor frequência que as anteriores.

Outro viés identificado na nuvem de palavras, diz respeito à possibilidade de atuação do TC como estratégia de desenvolvimento e geração de benefícios econômicos para uma determinada comunidade. Além das palavras "desenvolvimento" e “comunidade”, aparecem "negócio”, "valor”, “local”, “crescimento", "gerenciamento”, "país”, "trabalho”, “plano”, “público”. A partir da leitura dos resumos foi possível identificar que estas pesquisas se direcionam para a discussão de possibilidades de planejamento e desenvolvimento do TC, em parceria com as comunidades locais, para a geração de impactos econômicos positivos. Para isso, ressaltam ainda a importância do poder público local.

As Figuras 7 e 8, a seguir, apresentam a análise de similitude que, a partir da Teoria dos Grafos, identifica as ocorrências entre as palavras, separando-as em clusters e os relacionando entre si. A fim de uma melhor visualização das relações entre as palavras, optou-se por utilizar somente aquelas que mais se repetem no corpus textual, eliminando, assim, muitas palavras com poucas citações, como sugere Salviati (2017).

A Figura 7 mostra o resultado da análise de similitude para o recorte de palavras que se repetem dez ou mais vezes no corpus textual, onde identifica-se um total de 6 clusters, sendo o central e mais importante representado pelo termo "turismo". Neste cluster central estão as demais palavras que caracterizam grande parte dos artigos, tais como "pesquisa", "ciência", "universidade", "conhecimento", "conferência", “congresso", "internacional”, "comunidade". 
Ainda a partir da análise da Figura 7, observa-se a correspondência com a análise realizada na nuvem de palavras, uma vez que fica evidente a existência de um cluster voltado a representar os artigos que discutem o "desenvolvimento" do TC a níveis "local" e "nacional"; outro que representa os estudos sobre os "eventos" de esporte e de artes; e um terceiro que congrega os objetivos voltados à realização de "estudos", "observação", “análises”, envolvendo "métodos” científicos e os "participantes" das pesquisas.

Na Figura 8, a seguir, partiu-se para a confecção da análise de similitude considerando as palavras que se repetem cinco ou mais vezes nos resumos, o que resultou em um número maior de palavras contempladas e, consequentemente, na formação de novos clusters, sendo 14 no total.

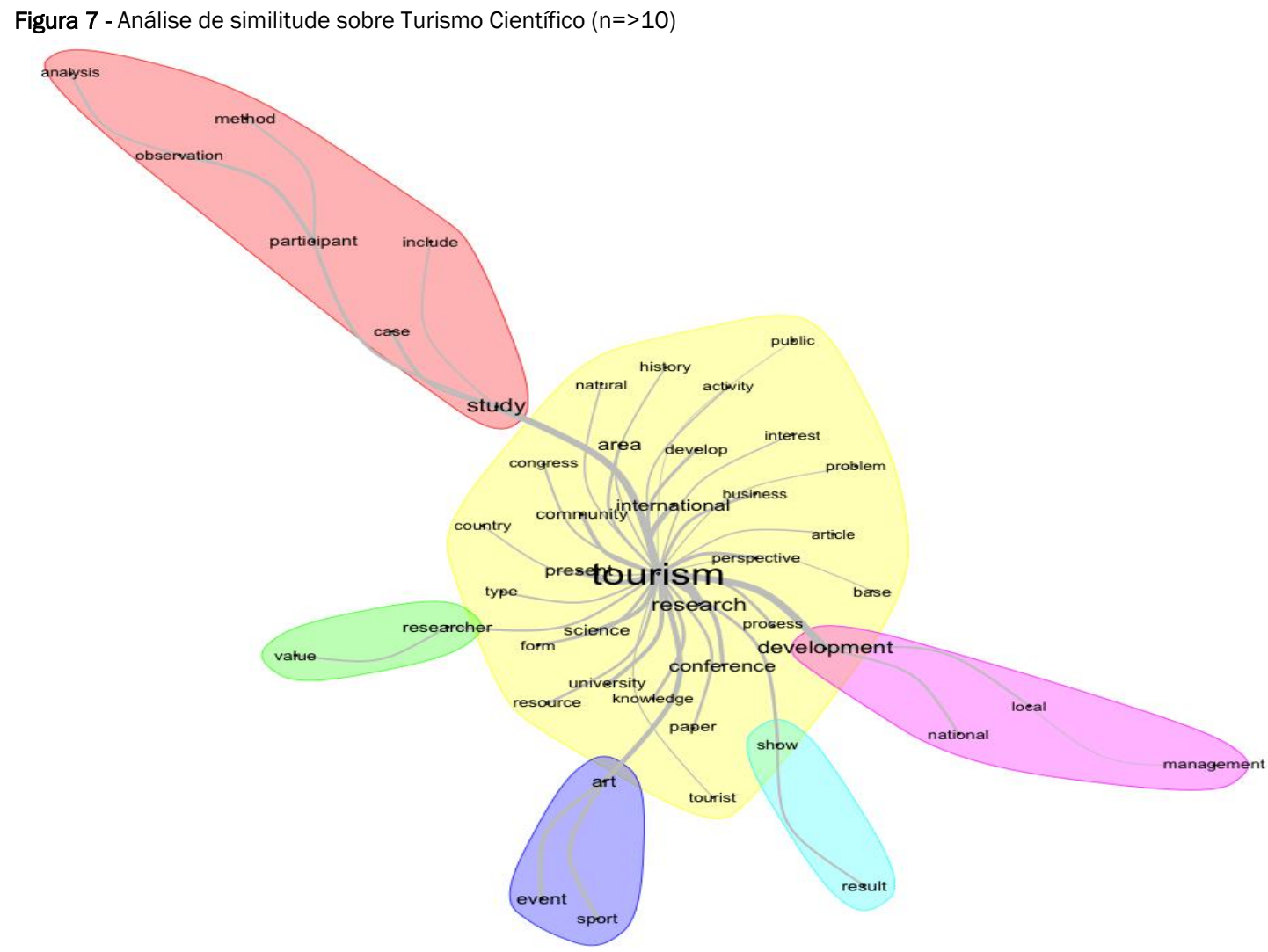

Fonte: Elaboração própria a partir do software Iramuteq com base nos resultados da pesquisa (2019).

Novamente mantêm-se centralidade no termo "turismo", assim como demonstrado nas Figuras 6 e 7. Os quatro clusters de maior tamanho que se destacam (sem contar o cluster central que congrega diversos clusters menores e palavras em comum entre eles), demonstram a reunião dos artigos que tratam de: 1) "eventos" (de arte, combate, esporte ou saúde), entendidos e analisados pelos autores a partir de uma perspectiva socioantropológica. 2) “áreas” de relevante interesse científico, principalmente aquelas voltadas à "conservação" - o TC muitas vezes é analisado nesses artigos como alternativa de proteção dos recursos naturais. 3) TC enquanto estratégia de educação, envolvendo novas "metodologias" de ensino, "observação", mudança de "comportamentos" - a disciplina de "química" aparece em relevância neste quesito. 4) "estudos" de "caso" sobre TC e estes como caminho para a realização de novas "pesquisas" e desenvolvimento de novos "métodos", envolvendo os "participantes".

A partir das análises apresentadas anteriormente, partiu-se para uma análise qualitativa mais minuciosa dos resumos selecionados, sendo possível, a partir disso, a criação de sete categorias que condensam os principais temas abordados pelos pesquisadores em torno do Turismo Científico, como em parte já representado nos clusters da análise de similitude (Figuras 7 e 8) e na nuvem de palavras (Figura 6). Essas categorias estão apresentadas e descritas na Tabela 5, a seguir: 
Figura 8 - Análise de similitude sobre Turismo Científico $(n=>5)$

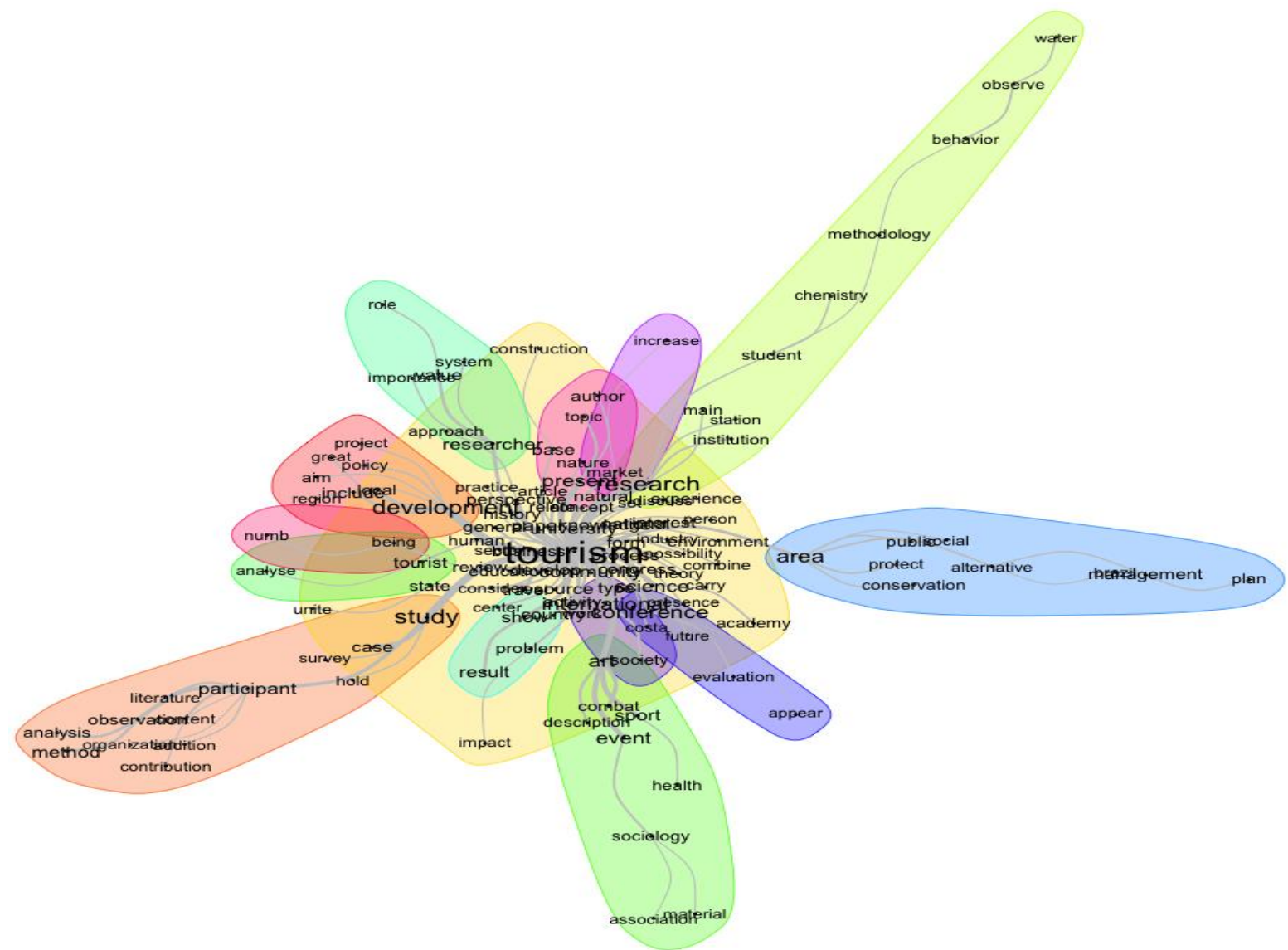

Fonte: Elaboração própria a partir do software Iramuteq com base nos resultados da pesquisa (2019).

Tabela 5 - Categorização dos artigos científicos

\begin{tabular}{|c|c|c|}
\hline Categorias & Quantidade de artigos & Descrição \\
\hline 1. Eventos (científico ou esportivo) & 10 & $\begin{array}{l}\text { Artigos que descrevem eventos com cunho científico ou esportivo, } \\
\text { com destaque para artigos no contexto das artes marciais. }\end{array}$ \\
\hline 2. Educação & 5 & $\begin{array}{l}\text { Artigos que tratam do turismo científico como estratégia de educa- } \\
\text { ção/ensino. }\end{array}$ \\
\hline 3. Viagem científica & 7 & $\begin{array}{l}\text { Artigos que tratam de viagens científicas de pesquisadores, profes- } \\
\text { sores, estudantes, para um local de interesse científico ou para cen- } \\
\text { tros de pesquisa. }\end{array}$ \\
\hline 4. Turismo de natureza & 8 & $\begin{array}{l}\text { Artigos que vinculam o turismo científico ao turismo de natureza, à } \\
\text { conservação de áreas protegidas e/ou práticas de ecoturismo. }\end{array}$ \\
\hline 5. Geoturismo/Geoparque & 4 & $\begin{array}{l}\text { Artigos que tratam de geoturismo e/ou geoparques em associação } \\
\text { ao turismo científico. }\end{array}$ \\
\hline $\begin{array}{l}\text { 6. Desenvolvimento socioeconô- } \\
\text { mico }\end{array}$ & 3 & $\begin{array}{l}\text { Artigos que tratam o turismo científico como possibilidade de desen- } \\
\text { volvimento socioeconômico de um local. }\end{array}$ \\
\hline 7. Teórico & 1 & $\begin{array}{l}\text { Artigos que têm como objetivo principal a discussão teórica sobre tu- } \\
\text { rismo científico. }\end{array}$ \\
\hline Total & 38 & \\
\hline
\end{tabular}

Fonte: Elaboração própria a partir dos softwares Mendeley e Excel com base nos resultados da pesquisa (2019).

Vale destacar que seis artigos analisados foram classificados em duas categorias diferentes, o que totalizou, na tabela anterior, em 38 classificações nas categorias estipuladas. Destes seis artigos, dois estão incluídos nas categorias "Geoturismo/Geoparque" e "Educação". Outros três estão incluídos nas categorias 
"Educação" e "Turismo de Natureza". E um artigo foi incluído nas categorias "Viagem científica" e "Turismo de natureza".

0 maior número de artigos contempla a categoria "Eventos" ( $n=10)$, que engloba eventos do tipo científico ou esportivo. Nestes artigos os autores abordam a organização de eventos como arenas de produção de conhecimento, sejam estes acadêmicos ou não. No que diz respeito aos eventos esportivos, vários artigos abordaram, com recorrência, o tema das artes marciais, principalmente os autores poloneses vinculados à "International Martial Arts and Combat Sports Scientific Society (IMACSSS)" e suas publicações no periódico "Ido Movement for Culture - Journal of Martial Arts Anthropology".

Na sequência, as categorias "Viagem Científica" $(n=7)$ e "Turismo de Natureza" $(n=8)$ foram as que reuniram maior número de artigos. A primeira contempla artigos que retratam viagens motivadas pela realização de pesquisas, aprimoramento educacional, intercâmbio científico. Vale ressaltar que estes destinos são entendidos pelos autores como de grande valor científico e se tornam atrativos turísticos para um nicho de viajantes. Assim, o Turismo Científico passa a ser associado às visitas, estadas ou viagens a lugares onde a natureza oferece possibilidades para se conhecer aspectos relacionados às ciências naturais. Pode também envolver o estudo e a análise de uma localidade ou de um objeto específico dessa área, relacionados, por exemplo, à fauna e à flora, ou ainda, ao estudo da cultura de um local, o que implica no envolvimento da comunidade autóctone como essencial para compreensões mais aprofundadas.

Nesse sentido, experiências de Turismo Científico têm sido compreendidas como forma de interpretação do espaço de uso turístico constituído de recursos patrimoniais naturais ou culturais, e ainda como via possível de medidas aplicadas à recuperação, conservação, divulgação e uso sustentável de atrativos (como demonstrado nas Figuras 7 e 8 ).

Já na categoria "Turismo de Natureza", o tema do TC é abordado na associação com viagens destinadas à áreas naturais de grande interesse para as práticas de lazer, ao mesmo tempo em que visam a proteção ambiental. Alguns, inclusive, identificam o TC como uma forma de turismo sustentável ou como subtipo do ecoturismo, envolvendo a produção de conhecimento científico a partir de atividades como espeleoturismo, observação de aves (birdwatching), estudos do meio em unidades de conservação, turismo de aventura com dimensão científica, dentre outras. Observou-se, portanto, a recorrência do termo "ecoturismo" como sinônimo de Turismo Científico ou de Natureza, o que precisa ser problematizado, uma vez que na literatura científica de turismo, o conceito de ecoturismo vem sendo questionado, nas últimas décadas, por muitas vezes não representar de fato a realização de práticas turísticas baseadas em um modelo compatível com a sustentabilidade ambiental das áreas visitadas.

Embora fosse possivel associar os artigos que tratam do "Geoturismo" ou do turismo delimitado em áreas denominadas "Geoparques" $(n=4)$ à categoria "Turismo de Natureza", optou-se por analisá-los em categoria específica. Isso porque 4 dos artigos encontrados dão ênfase a esta modalidade por ela apresentar peculiaridades, haja visto o conjunto de características que marcam a criação de geoparques. Este número de artigos mostra também a concentração de áreas do conhecimento agregadas em torno da criação de geoparques.

Evidencia-se, na produção analisada, que o TC tem se traduzido, em muitos países, por experiências de geoturismo. Esse talvez seja, atualmente, o campo de maior abrangência e crescimento quando se pensa numa atividade que alia visitação e ciência. 0 geoturismo é uma realidade em alguns países do mundo, como por exemplo em Portugal - no arquipélago dos Açores e no Parque Natural das Serras de Aire e Candeeiros. Tem-se conhecimento também da existência de muitos geoparques localizados na Europa (Portugal, Espanha, Reino Unido), Austrália, Malásia, EUA e Irã, onde a prática do geoturismo já se configura como realidade inovadora para a promoção do desenvolvimento sustentável (Moreira, 2014), e que são objetos de análise de alguns dos artigos identificados neste trabalho.

No caso do Brasil, a produção nacional sobre TC tem abordado diferentes perspectivas, no entanto, o tema dos "geoparques", associado ao "geoturismo", tem assumido uma recorrência considerável, diante da grande potencialidade apresentada para a prática do TC. Há em curso muitas propostas de criação de geoparques como forma de gestão territorial apoiada no geoturismo (no campo ou na cidade), geograficamente localizados principalmente nos estados de Minas Gerais (Caminho dos Diamantes, Parque 
Estadual Serra do Rola Moça, e Ouro Preto - Geologia e Geomorfologia relacionada ao minerais preciosos); Rio Grande do Norte (Geoparque Seridó); Maranhão, na cidade de Carolina (Parque Chapada das Mesas); e no Pantanal brasileiro (região de Bonito, no Mato Grosso do Sul), que é atualmente uma das áreas que mais se destaca nesse segmento (Nascimento et. al, 2015). No ambiente urbano destacam-se as propostas de geoturismo paleontológico no centro da cidade do Rio de Janeiro, por exemplo (Medeiros e Polck, 2017).

Partindo para a categoria “Educação" $(n=5)$, foram identificados artigos que apresentam o Turismo Científico como estratégia de educação num sentido mais amplo, ou ainda, o ensino relacionado a disciplinas específicas, tais como biologia, física, química, geografia, geologia e história. Nesses casos, o TC pode se apresentar como uma experiência em que o turista terá contato com a cultura do visitado, contato que pode gerar a produção do conhecimento científico, daí poder ser também classificado como um subtipo do turismo de intercâmbio e/ou turismo educativo, por permitir o aprimoramento profissional ou a realização de programas específicos para aprendizado e treinamento.

A categoria "Desenvolvimento Socioeconômico" $(n=3)$ reúne os artigos que apresentam o TC como estratégia de desenvolvimento e promoção do turismo em determinados locais (como também demonstrado nas Figuras 7 e 8). Vale destacar que estes artigos evidenciam a importância da participação das comunidades nesses processos.

Os estudos desta categoria reforçam ainda a importância de pesquisas estimuladas pelo Turismo Científico em áreas naturais, sobretudo com a presença de comunidades pobres. Apresentam seus resultados apontando para a criação de propostas de desenvolvimento do turismo que valorizem e democratizem o acesso à produção de conhecimento como forma de contribuir para a geração de iniciativas de TC que gerem impactos positivos nas comunidades locais. O TC, como forma de turismo sustentável, é apresentado, portanto, como perspectiva de desenvolvimento para várias economias, dentre elas, as menos desenvolvidas.

Por fim, foi identificado apenas um artigo que trata o TC a partir de uma discussão teórico-epistemológica (categoria "Teórico", n=1). Nesta categoria se encaixa um estudo sobre uma obra monográfica de Wojciech Cynarski, na qual Cynarski aborda o "Turismo de Ciência” na perspectiva da sociologia visual. O estudo realizado destaca o debate sobre o turismo de negócios, assim como sobre as singularidades do conceito de turismo de conferências e congressos (retratado como fenômeno intelectual). Dentre as conclusões do estudo, destaca-se a importância do trabalho de Cynarski, enquanto adição valiosa ao estudo do turismo e, também, enquanto importante publicação científica sobre TC, uma vez que aponta para a evolução do campo de conhecimento e indica prescrições para futuros pesquisadores de TC.

\section{CONSIDERAÇÕES FINAIS}

Este trabalho teve por objetivo apresentar uma revisão sistemática da literatura sobre Turismo Científico, nos contextos nacional e internacional. Para tal, foi realizada uma análise bibliográfica e bibliométrica da amostra identificada. Nesse sentido, foram analisados quali-quantitativamente 32 artigos científicos, a partir de diferentes softwares, que são: Mendeley, Excel, QGis e Iramuteq. Por meio do Mendeley foi possível reunir os trabalhos obtidos nas bases de dados; selecionar e organizar os artigos de interesse para a pesquisa; e realizar a leitura dos resumos e categorização dos artigos. 0 Excel permitiu analisar quantitativamente os dados e gerar figuras e tabelas. Com o QGis foi possível mapear as áreas de interesse dos estudos de caso sobre TC que compõem a amostra desta pesquisa, com o objetivo de identificar algumas das principais práticas relativas ao tema em questão. E o Iramuteq permitiu gerar análises qualitativas de similitude e nuvem de palavras que foram apresentadas em forma de figuras.

Por meio da compilação e entendimento dos conceitos anteriores à investigação, que já foram objeto de tratamento analítico em estudos precedentes, a revisão de literatura visou contribuir para a compreensão das bases científicas e teóricas que compõem a construção do conhecimento no campo de interesse (Panosso Netto e Nechar, 2014).

Foi possível verificar que os termos com maior repetição (verificados para atender à Lei de Zipf), corroboram com as categorias que abrangem grande parte da produção em TC até o momento, quais sejam: a prática do turismo com objetivo de apreensão de conhecimento científico; a viagem para participação em eventos 
desta ordem ou a análise da realização de eventos científicos; a correlação do turismo com o esporte, em especial, as artes marciais; e o ecoturismo ou a prática do turismo com fins de visitação a áreas naturais.

Da mesma forma, a avaliação do corpus textual permitiu conferir destaque para, pelo menos, quatro conjuntos de categorias:

1) Eventos e Congressos Científicos ou Esportivos: a repetição dos resultados para os termos "conferência" e "evento" corroboram tal análise, uma vez que diversos artigos têm como foco a discussão da importância da realização de um determinado evento científico ou esportivo. Nesse contexto, os eventos relacionados às artes marciais e a outros esportes têm relevância nos artigos de TC, como já discutido anteriormente. Estes artigos relatam ainda as viagens de professores e estudantes a esses eventos e a diversos centros de pesquisa ou áreas de grande valor científico, com destaque para as áreas naturais. Trata-se de uma abordagem de diferentes dimensões do turismo de congressos, sobretudo com perspectivas teóricas antropológicas e sociológicas do turismo.

2) Turismo de Natureza, Geoturismo e Parques: o estudo em tela sugere que a evolução do tema "Turismo Científico" é fruto das análises empíricas desenvolvidas, por exemplo, em áreas naturais e/ou culturais de relevante interesse científico, ou ainda, experiências de geoturismo e ecoturismo que aliam visitação e ciência, para pesquisadores de uma área do conhecimento e/ou visitantes/turistas interessados na temática. 0 geoturismo e o turismo científico se apresentam como atividades inter-relacionadas que se realizam em áreas protegidas. Trata-se de uma nova compreensão do geoturismo que inclui não apenas as visitas aos objetos abióticos da natureza, mas sua ampla cognição, desde as estruturas geológica e história, passando pelo desenvolvimento de formas de relevo, problemas ambientais, proteção da natureza, impacto no crescimento econômico da região até contextos históricos e culturais. Estas linhas de estudos podem auxiliar de diferentes formas na recuperação, conservação, divulgação e uso sustentável de atrativos turísticos.

3) Viagens Científicas e Educacionais: neste caso as viagens estão associadas às motivações de aprimoramento educacional e de intercâmbio científico. No que concerne à educação, se tem entendido que a viagem com este fim pode proporcionar estratégias educacionais de sentido mais amplo, quando o contato físico engrandece a experiência de aprendizado. Os estudos sugerem que o Turismo Científico relacionado à viagem e à educação pode se tornar referência para a conservação de patrimônios, sobretudo por permitir a maior divulgação e popularização da ciência de maneira lúdica, associada ao lazer.

4) Desenvolvimento Socioeconômico: muitos artigos evidenciam potencialidades para a promoção do TC como alternativa de desenvolvimento econômico das comunidades, assim como meio para a valorização e proteção dos seus recursos naturais e culturais. Nesse sentido, são apresentados diversos estudos de caso localizados na China, Rússia, Costa Rica, Venezuela, Brasil, Portugal, Nova Guiné.

Por fim, a análise das categorias apresentadas aponta que o TC não parece se comportar apenas como um segmento de mercado, embora esta tendência tenha se apresentado em parte da literatura analisada, quando classificado como subtipo de segmentos de turismo já consolidados. Por outro lado, há um forte apontamento para o entendimento do TC como um dos paradigmas do turismo sustentável.

Pode-se identificar algumas limitações desta pesquisa. Em primeiro lugar, apesar dos resultados proporcionados com o Iramuteq, este software não reconheceu algumas palavras importantes para a pesquisa, tanto na análise de similitude, como na nuvem de palavras. Termos como "científico", "marciais", "ecoturismo", "ecológico", "geoparque", dentre outros, não compuseram estas análises. Isto demonstra uma limitação do vocabulário deste software. Futuros estudos devem avaliar a possibilidade de utilização de outras ferramentas para análises mais aprofundadas, ou aguardar uma atualização do vocabulário do Iramuteq.

Outra limitação se dá na seleção da amostra, os próximos estudos podem ampliar a busca usando outros termos associados ao tema nas palavras-chave e/ou em outros parâmetros de busca e/ou em outras bases de dados. Sobre as bases de dados, importa destacar, também, que este estudo não capturou um dos dois primeiros artigos científicos sobre TC, citados no início da segunda seção deste trabalho. Trata-se do artigo de autoria de Jan Laarman e Richard Perdue, publicado na "Tourism Management", em 1989 (Campos, 2018). Novamente, o que sugere a ampliação das bases de dados nos próximos estudos bibliométricos 
sobre esta temática. Vale destacar ainda que foram recuperados poucos artigos do idioma espanhol, o que pode também justificar a inclusão de novas bases.

É possível concluir que o método bibliométrico pode colaborar na sistematização da produção científica em um determinado campo do saber e apontar novas áreas de investigação a serem exploradas, buscando a consolidação de campos da ciência, tais como o Turismo e o Turismo Científico. Nesta pesquisa evidenciase a necessidade de publicações que possam aprofundar a discussão teórica sobre TC, assim como a delimitação de um marco conceitual que poderá ser utilizado como norte para os estudos e as ações de fomento ao TC implementadas em diversas partes do mundo.

\section{AGRADECIMENTOS}

Os autores agradecem o apoio financeiro concedido pela Pró-Reitoria de Extensão e Cultura e Pró-reitora de Pós-Graduação, Pesquisa e Inovação da Universidade Federal do Estado do Rio de Janeiro (UNIRIO), para, respectivamente: projeto de extensão "Turismo Científico: “Caminhos de Darwin” na cidade do Rio de Janeiro"; e projeto de pesquisa "Turismo Científico no Brasil: entre a ciência e a prática turística”. Agradecem, também, a parceria dos discentes envolvidos nos projetos, dos colegas pesquisadores da UNIRIO e dos pesquisadores da Casa da Ciência, Instituto de Geociências e do Programa de Pós-Graduação em Engenharia de Transportes/Coppe, da Universidade Federal do Rio de Janeiro (UFRJ).

\section{REFERÊNCIAS}

Albach, V.M. (2015). A difusão da pesquisa em geografia do turismo na ibero-américa [Tese de Doutorado, Universidade Federal do Paraná]. Recuperado mar. 3, 2019, de https://acervodigital.ufpr.br/handle/1884/41332.

Benson, A. (2005). Research tourism: professional travel for useful discoveries. In: M. Novelli, Niche Tourism: contemporary issues, trends and cases (pp. 133-142). Oxford: Elsevier.

Bosak, K. (2015). Scientific tourism and sustainable development in the Aysén region of Chile. In: S. Slocum, C. Kline, A. Holden, Scientific tourism: researchers as travellers (pp. 117-130). New York: Routledge.

Bourlon, F., Mao, P., \& Osorio, M. (2011). El turismo científico en Aysén, un modelo de valorización territorial, basado en el patrimonio y actores locales. Revista Sociedad Hoy - Universidad de Concepcion. Recuperado nov. 10, 2020, de https://www.researchgate.net/publication/281447886_Turismo_cientifico modelo de valorizacion territorial Sociedad Hoy 2011.

Bravo, E.F.O., Cuadrado, C.E.A., Belema, L.A.A., \& Sáenz, M.A.V. (2017). El turismo científico y su contribución al desarrollo local sostenible en Ecuador. Caso de estudio. Revista DELOS: Desarrollo Local Sostenible, n. 29. Recuperado nov. 10, 2018, de http://www.eumed.net/rev/delos/29/turismo-ecuador.html.

Busalim, A.H., \& Hussin, A.R.C. (2016). Understanding social commerce: A systematic literature review and directions for further research. International Journal of Information Management, 36 (6), 10751088. https://doi.org/10.1016/j.ijinfomgt.2016.06.005

Campos, S.A. (2018). O turismo científico na região Alentejo: estudo exploratório acerca do perfil e motivações do visitante dos Centros Ciência Viva [Dissertação de Mestrado, Universidade de Évora], (pp. 309). Recuperado mar. 03, 2019 de https://dspace.uevora.pt/rdpc/handle/10174/23162..

Chueke, G.V., \& Amatucci, M. (2015). O que é bibliometria? Uma introdução ao Fórum. Intertext. 10(2), 1-5. https://doi.org/10.18568/1980-4865.1021-5

Corneloup, J. (2009). Comment est abordée la question de l'innovation dans les sciences sociales? Revue de Géographie Alpine, 97(1), 113-128. https://doi.org/10.4000/rga.828

Cynarski, W., Duricek, M. (2014). Scientific tourism. Self-realisation, dialogue-cultural and sacral dimensions. IDO Movement For Culture. Journal of Martial Arts Anthropology, 14(4), 39-45. https://doi.org/10.14589/ido.14.4.5

Day, P. (2019). Scientific Tourism: Some Places on the Way. Independently Published.

Ereshko F.I. (2006). Nauchnyiy turizm - tsel i sredstvo progressa v razvitii regionov [Scientific tourism - the purpose and means of progress in development of the regions]. apud Filippova, V., Savvinova, A., 
Danilov, Y., Gadal, S., \& Kamičaityté-Virbašienéi, J. (2017). The Study of Cultural Landscapes of Central Yakutia for the Development of Scientific Tourism, Journal of Sustainable Architecture and Civil Engineering, 4(21), 5-16.

Filippova, V., Savvinova, A., Danilov, Y., Gadal, S., \& Kamičaityté-Virbašienéi, J. (2017). The Study of Cultural Landscapes of Central Yakutia for the Development of Scientific Tourism, Journal of Sustainable Architecture and Civil Engineering, 4(21), 5-16. https://doi.org/10.5755/j01.sace.21.4.19501

Galvão, T.F., \& Pereira, M.G. (2014). Revisões sistemáticas da literatura: Passos para sua elaboração. Epidemiol. Serv. Saúde, 23(1), 183-184. http://dx.doi.org/10.5123/S1679-49742014000100018

Ganong L.H. (1987). Integrative reviews of nursing research. Res Nurs Health, 10(1), 1-11. https://doi.org/10.1002/nur.4770100103

Laarman, J., \& Perdue, R. (1989). Science tourism in Costa Rica. Annals of Tourism Research, 16(2), 2052015. https://doi.org/10.1016/0160-7383(89)90068-6

Laing, J.H. (2010). Science tourism: exploring the potential for astrobiology funding and outreach. Astrobiology Science Conference. Recuperado nov. 10, 2018, de https://www.Ipi.usra.edu/meetings/abscicon2010/pdf/5047.pdf.

Laville, C., \& Dionne, J. (1999). A construção do saber: manual de metodologia da pesquisa em ciências humanas. Porto Alegre: Artmed; Belo Horizonte: Editora UFMG.

Margoni, C.C. (2015). Turismo científico: conhecimento produzido em viagens. In: P. A. Netto, \& M. G. R. Ansarah, Produtos turísticos e novos segmentos de mercado: planejamento, criação e comercialização (pp. 163-173). São Paulo: Manole.

Medeiros, M.A.M., \& Polck, M.A.R. (2017). Geoturismo Paleontológico no centro histórico do Rio de Janeiro, Geociências, 36(1), 118-137.

Mieczkowskil, Z. (1995). Environmental Issues of Tourism and Recreation. United States of América: University Press of América.

Ministério da Ciência, Tecnologia, Inovações e Comunicações (MCTIC). Popularização da ciência e tecnologia. Recuperado mar. 10, 2020 de https://www.mctic.gov.br/mctic/opencms/ciencia/SEPED/popularizacaoCeT/ cientifica/A popularizacao da ciencia e tecnologia e a divulgacao cientifica.html.

Moesch, M.; Beni, M.C. (2015). Do discurso sobre a ciência do turismo para a ciência do turismo. Recuperado jan. 02, 2020, de https://www.anptur.org.br/anais/anais/files/12/48.pdf

Molokacova, L., \& Molokac, S. (2011). Scientific tourism: tourism in science or science in tourism? Acta Geoturistica, 2(1), 41-45.

Montaner Montejano, J. (2001). Estrutura do mercado turístico. São Paulo: Roca.

Moreira, J.C. (2014). Geoturismo e interpretação ambiental. 1st ed. rev. and enl. Ponta Grossa: Editora UEPG. ISBN 978-85-7798-213-4. Recuperado mar. 13, 2020, de http://books.scielo.org/id/v4ddr/pdf/moreira-9788577982134.pdf.

Morse, M.A. (1997). All the world's a field: a history of the scientific study tour. Progress in Tourism and Hospitality Research, 3, 257-269. https://doi.org/10.1002/(SICl)10991603(199709)3:3<257::AID-PTH72>3.0.CO;2-U

Nascimento, M.A. L., Gomes, C.S.C.D., \& Soares, A.S. (2015). Geoparque como forma de gestão territorial interdisciplinar apoiada no geoturismo: caso do Projeto Geoparque Seridó. Revista Brasileira de Ecoturismo, 8(2), 347-365. https://doi.org/10.34024/rbecotur.2015.v8.6451

Novelli, M. (2005). Niche Tourism: contemporary issues, trends and cases. Oxford: Elsevier.

Organização das Nações Unidas (ONU). (2015). Transformando nosso mundo: a agenda 2030 para o desenvolvimento sustentável. Recuperado mar. 13, 2020, de https://nacoesunidas.org/pos2015/agenda2030/.

Panosso-Netto, A., \& Nechar, M.C. (2014). Epistemologia do Turismo: escolas teóricas e proposta crítica. Revista Brasileira de Pesquisa em Turismo, 8(1), 120-144. https://doi.org/10.7784/rbtur.v8i1.719

Revilla, M.R.G, \& Moure, O.M. (2017). Turismo científico y ciudades del futuro. International Journal of Scientific Management and Tourism, 3(1), 123-130. 
Salvati, M.E (2017). Manual do Aplicativo Iramuteq. Recuperado mar. 03, 2020, de http://www.iramuteq.org/documentation/fichiers/manual-do-aplicativo-iramuteq-par-maria-elisabeth-salviati.

Sonego, M., \& Echeveste, M.S. (2016). Seleção de métodos para modularização no desenvolvimento de produtos: Revisão sistemática. Production, 26(2), 476-487. http://dx.doi.org/10.1590/0103$\underline{6513.138413}$

Souza, M.T., Silva, M.D., \& Carvalho, R. (2010). Revisão integrativa: o que é e como fazer. Einstein, 8(1), 102106. http://dx.doi.org/10.1590/s1679-45082010rw1134

Schlindwein, M.N., Akaki, A.T., \& Laganaro, N.M. (2011). Atividades de observação do comportamento de Sotalia guianensis como subsídio para o Turismo Científico no Parque Estadual Ilha do Cardoso Cananéia (SP). Revista Brasileira de Ecoturismo, 4(2), 196-207. https://doi.org/10.34024/rbecotur.2011.v4.5914

\section{Informações sobre os autores:}

\section{Bruna Ranção Conti}

Professora Adjunta do Departamento de Turismo e Patrimônio da Universidade Federal do Estado do Rio de Janeiro (UNIRIO); Professora Permanente do Programa de Pós-Graduação em Turismo da Universidade Federal Fluminense (UFF). Graduação em Turismo (Universidade Federal de Juiz de Fora - UFJF). Mestre em Psicossociologia de Comunidades e Ecologia Social (Universidade Federal do Rio de Janeiro - UFRJ). Doutora em Políticas Públicas, Estratégias e Desenvolvimento (Universidade Federal do Rio de Janeiro - UFRJ).

Contribuições no trabalho: Concepção da pesquisa, revisão da literatura, coleta de dados, análise e discussão dos resultados.

E-mail: bruna.conti@unirio.br

Orcid: https://orcid.org/0000-0003-0562-0834

\section{Maria Jaqueline Elicher}

Professora Adjunta do Departamento de Turismo e Patrimônio da Universidade Federal do Estado do Rio de Janeiro (UNIRIO). Bacharel e Licenciada em Geografia (Universidade Federal de Santa Catarina - UFSC). Mestre em Geografia (Universidade Federal de Santa Catarina - UFSC). Doutora em Geografia (Universidade Federal Fluminense - UFF).

Contribuições no trabalho: Concepção da pesquisa, revisão da literatura, coleta de dados, análise e discussão dos resultados.

E-mail: maria.elicher@unirio.br

Orcid: https://orcid.org/0000-0002-4085-9827

\section{Joice Lavandoski}

Professora Adjunta do Departamento de Turismo e Patrimônio da Universidade Federal do Estado do Rio de Janeiro (UNIRIO); Professora Colaboradora do Programa de Pós-Graduação em Turismo da Universidade Federal Fluminense (UFF). Graduação em Turismo (Universidade de Caxias do Sul - UCS). Mestre em Turismo (Universidade de Caxias do Sul - UCS). Doutora em Turismo (Universidade do Algarve - UALG). Contribuições no trabalho: Concepção da pesquisa, revisão da literatura, coleta de dados, análise e discussão dos resultados.

E-mail: joice.lavandoski@unirio.br

Orcid: https://orcid.org/0000-0002-7324-1134 